\title{
A theoretical and experimental framework for the formation of mixed anodic films on combinatorial aluminium-cerium alloys
}

\author{
Khurram Shahzad a, Shaukat Ali Lone ${ }^{a}$, Cezarina Cela Mardare ${ }^{\mathrm{a}, \mathrm{b}}$, Andrei Ionut Mardare ${ }^{\mathrm{a}}$, \\ Achim Walter Hassel ${ }^{\mathrm{a}, \mathrm{b}, *}$ \\ a Institute of Chemical Technology of Inorganic Materials, Johannes Kepler University Linz, Altenberger Str. 69, 4040 Linz, Austria \\ ${ }^{\mathrm{b}}$ Christian Doppler Laboratory for Combinatorial Oxide Chemistry (COMBOX) at the Institute of Chemical Technology of Inorganic Materials, Johannes Kepler \\ University Linz, Altenberger Str. 69, 4040 Linz, Austria
}

\section{A R T I C L E I N F O}

\section{Article history:}

Received 28 January 2020

Revised 26 August 2020

Accepted 21 September 2020

Available online 7 October 2020

\section{Keywords:}

Cerium

Anodizing

Combinatorial library

Scanning droplet cell microscopy

Rare-earth oxides

\begin{abstract}
A B S T R A C T
Anodizing promises fast, cost-effective, and precise fabrication of mixed metal oxides from alloys of complex chemistries and compositions. Applicable to a whole class of valve metals and their alloys, this versatile fabrication method has found new dimensions of its applicability to a unique combination of valve and non-valve metals in the quest of finding new applications. Hereby the fabrication of anodic passive films on Al-Ce thin-film combinatorial alloy library covering 1.5 to 10.5 at.\% Ce in a phosphate buffer electrolyte having $\mathrm{pH}=8.3$ is demonstrated. Few nanometre thin dielectric films were attained through the automated localized anodizing using scanning droplet cell microscopy (SDCM). Electrochemical measurements suggest a good correlation among alloy composition, film thickness, relative permittivity as well as film resistance. It is inferred that the formation factor, $k$ greater than unity and stable growth of compact composite film is attainable through thermodynamic selection of electrolyte and Gibbs free energy minimization criteria.
\end{abstract}

(c) 2020 Published by Elsevier Ltd.

\section{Introduction}

Rapidly growing high-tech industry demands an urgent need for new materials fabrication at an accelerating pace in a costeconomic fashion. In contrast to traditional approaches, combinatorial experiments [1] high-throughput calculations [2,3] as well as accelerated materials discovery have gained increased attention in recent years. In this regard, the rapid synthesis of thin film combinatorial libraries is crucial for providing many solid-state material solutions [4]. Mixed metallic alloys having new chemistries and structures are important means to tune the properties, which may be superior to that of each constituent element [5,6].

Regarding high-tech applications, rare-earth elements (REEs) [7] often called industrial vitamin or treasury of advanced materials have gained an increasingly important role in the development of traditional industries [8,9]. It is well-known that the nature of $4 f$ orbitals gives rare-earth (RE) unique electronic, magnetic and catalytic properties. These $4 f$ orbitals are buried inside the atom and are shielded by $4 d$ and $5 p$ electrons [7]. The unusual properties of RE can be exploited either alone or in combination with other met-

\footnotetext{
* Corresponding author at: Institute of Chemical Technology of Inorganic Materials, Johannes Kepler University Linz, Altenberger Str. 69, 4040 Linz, Austria.

E-mail address: achimwalter.hassel@jku.at (A.W. Hassel).
}

als to accomplish new applications that are impossible with other main group or transition metals elements. Cerium (Ce), as the first and most abundant element in lanthanoid series [10,11] has attracted more scientific attention from the researchers of materials science, physics, chemistry, and engineering background. This is because of the fascinating applications of Ce oxide in various engineering and biological applications [12-25].

In 2011, REEs particularly gained political and media attention, when supply constraints in China raised the prices by up to $20,000 \%$ [8]. Many of RREs are considered a by-product in RE mining. Sims et al. [26] reported the use of one of these by-product elements like Ce for high volume application in conjunction with $\mathrm{Al}$. By doing so, the global supply of more valuable RREs such as those used in permanent magnets can be stabilized. Due to large demand and limited availability of REEs, intelligent strategies where a small amount of REEs and their oxides can play a crucial role are needed to balance the supply and demand. For instance, the very low demand for $\mathrm{Ce}$, the most abundant $\mathrm{RE}$ will subsequently contribute to the instability of the global RE market as in high-temperature applications of Al-Ce alloys [26]. Numerous techniques have been reported in the literature for fabricating materials containing Ce oxide [27-32]. None of these techniques describe the fabrication of thin Ce oxide films especially the systematic investigation of the effect of Ce concentration on the resulting oxide properties in 
Al-Ce alloys. Literature data reveals that among various oxidation techniques, anodic polarization is a simple, fast, environmentally friendly, and the cost-effective method of thin film oxidation for an alloy having complex chemistry [33-36].

$\mathrm{RE}$ oxide may be incorporated into the anodic films on $\mathrm{Al}$ by the following ways: (a) anodizing of $\mathrm{Al}$ in an electrolyte containing RE anions, (b) Anodizing of Al-RE alloys, (c) combination of anodizing and various post-treatments e.g. sol-gel coating, physical, and chemical vapor deposition coatings of RE oxides. Among all these, only approach (b) may incorporate RE oxide uniformly to understand the fundamental properties of resulting mixed-oxide films and simultaneously studying the influence of REEs [37]. Crossland et al. investigated the Ce role in limiting corrosion of $\mathrm{Al}$ alloys and found that $\mathrm{Ce}$ species acts as an inhibitor for Al in weakly and strongly alkaline solution [37]. In recent years, cerium salt solutions have attracted attention for the corrosion researchers as an alternative treatment to replace chromates from Al alloys. These salt solutions generate oxides/hydroxides coatings and generally contain $\mathrm{Ce}^{3+}$ and $\mathrm{Ce}^{4+}$ on the alloy surface $[37,38]$. Besides these electrochemical applications, composite anodic films formed by multi-element anodizing may be used to alter the dielectric properties, capacitance of various capacitors, etc. Nevertheless, the susceptibility of oxide films against dissolution and its transformation from one morphology (barrier-type) to another (porous type) during electrochemical fabrication is sensitive to the $\mathrm{pH}$ of the electrolyte. Additionally, it is an extremely time-consuming effort to find an electrolyte where oxidation of combinatorial alloys is favorable without appreciable dissolution of either element of the parent alloy. Owing to this reason, very little information on the oxidation behavior of Al-Ce alloys and correlation of composition, structure, morphology, and resulting thin film properties is available in the literature.

Therefore, in the present study, systematic investigation of the effect of Ce concentration on Al-Ce combinatorial alloys has been carried out in a phosphate buffer electrolyte ( $\mathrm{pH}$ 8.3). A different scheme is used here to integrate high-throughput computations and combinatorial experimental work. The high-throughput calculations in the form of Pourbaix and phase diagrams using DFT calculations and commercial softwares were used to maximize thermodynamic prediction of possible stable phases in a complex Al$\mathrm{Ce}-\mathrm{H}_{2}-\mathrm{O}_{2}-\mathrm{P}$ system and rapid identification of suitable electrolytes for multi-element anodizing, while the electrolyte choice was examined using combinatorial experiments on Al-Ce system at low concentration of Ce. The effect of electrolyte was examined on dielectric permittivity and film resistance. Alloy library and resulting films were characterized using XRD (X-ray diffraction), SEM (scanning electron microscopy), and combined potentiodynamic (CV) and electrochemical impedance spectroscopy (EIS) techniques to map the film properties as a function of Ce concentration.

\section{Experimental}

A thin metallic alloy library of $\sim 500 \mathrm{~nm}$ thickness was prepared by simultaneous thermal evaporation of $\mathrm{Al}$ and $\mathrm{Ce}$ on borosilicate float glass substrates (VWR International $\mathrm{GmbH}$ ) having dimensions of $2.6 \times 7.6 \mathrm{~cm}^{2}$. Prior to deposition, glass substrate cleaning was carried out by sequential ultrasonication in acetone, isopropanol, and water. The deposition system was designed and self-developed for thin film combinatorial libraries. For this purpose, two independent tungsten thermal boats (J. K. Lesker) containing either $\mathrm{Al}$ (99.95\%, Goodfellow) or Ce, (99.99\% Smart Elements) were placed eccentrically in relation to the center axis normal to the sample. This allowed the fabrication of an Al-Ce compositional gradient along the substrate. Before commencing with the deposition process, the system was pumped down to a base pressure of $1 \times 10^{-5} \mathrm{~Pa}$. The compositional gradient control is ob-
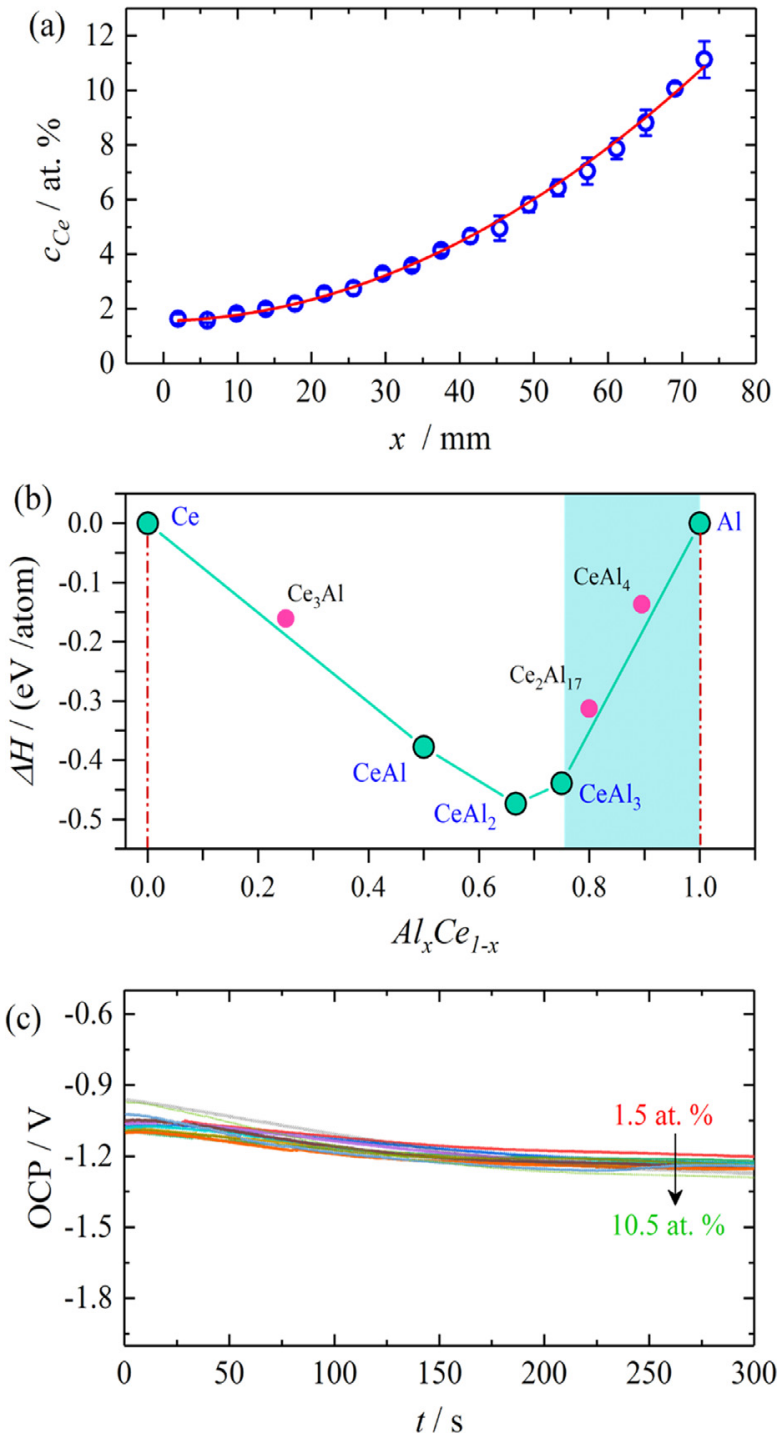

Fig. 1. (a) Surface concentration mapping of Al-Ce alloy library along the substrate length, (b) Phase diagram of Al-Ce system generated from DFT calculations (c) Open circuit potential (OCP) measurement at 14 different concentrations of Al-Ce alloys for $300 \mathrm{~s}$.

tained by modifying the individual deposition rates, which are insitu monitored by quartz crystal microbalances (QCM - Inficon). Deposition rates of 0.80 and $0.18 \mathrm{~nm} \mathrm{~s}^{-1}$ were used for $\mathrm{Al}$ and $\mathrm{Ce}$, respectively and both sources used a deposition distance of $120 \mathrm{~mm}$. A final film thickness of $500 \mathrm{~nm}$ was obtained at the center of the Al-Ce library.

Scanning energy-dispersive X-ray (SEDX) spectroscopy was used for mapping the Al-Ce thin film library. This technique is available in the same experimental cluster the so-called CALMAR and thus allowed an ultra-high vacuum transfer of the sample after deposition right into the SEDX scanner. The quantitative analysis of different alloys located at discrete positions along the sample was performed using IDFix software (remX GmbH). Characteristic $\mathrm{X}$-rays resulting from surface irradiation with $20 \mathrm{keV}$ electrons in a spot size with a diameter of $500 \mu \mathrm{m}$ were analyzed by a Si drift detector (SDD, remX GmbH). As a result, the SEDX mapping precisely provides the location of individual Al-Ce alloys along the entire library. A total compositional spread of 9.5 at.\% was obtained. The Ce amount varied between 1.0 and 10.5 at.\% along the library (Fig. 1a). Complementary, the Al concentration varied be- 
tween 99.0 and 89.5 at.\%. This describes a compositional resolution of 0.13 at.\% $\mathrm{mm}^{-1}$. If (typical) 1 at.\% precision is desired for Al-Ce alloy identification along the library, then a virtual stripe more than $7 \mathrm{~mm}$ long may be defined as hosting a single alloy. This rather large surface is quite convenient for various followup measurements in order to characterize compositionally induced changes in Al-Ce alloys. It is worth mentioning here that the compositional spread of a library is limited by the particularities of the cosine law governing the thickness uniformity of alloying element taken separately along the substrate. Ce contents greater than 10 at.\% would mean preparation of a new library. Higher Ce contents would result in the formation of various intermetallics (Fig. 1b), therefore, the Ce contents are restricted to around $10 \%$. The phases in the evaporated films were identified using X-ray diffraction (XRD) in $\theta-2 \theta$ (Bragg-Brentano) and $\omega-2 \theta$ with $\omega=3^{\circ}$ (grazing incidence) geometries. $\mathrm{CuK}_{\alpha}$ radiation was employed for these measurements. Additionally, surface morphologies of Al-Ce alloy thin films before and after anodizing were examined using scanning electron microscopy (SEM - FEI Philips XL30 ESEM FEG). X'Pert HighScore software using PDF3 database was employed for phases identification.

All electrochemical measurements on the thermally evaporated alloy library were performed using a three-electrode microelectrochemical flow cell at room temperature and atmospheric pressure [39]. The SDCM contains two channels in V-geometry serving as inlet and outlet for the electrolyte. The SDCM cell has an opening at the tip and is encircled with a silicone sealing that prevents electrolyte leakage. A platinum wire and $\mathrm{Hg} / \mathrm{Hg}_{2} \mathrm{Cl}_{2}$ deposited on Au wire act as a counter and $\mu$-reference electrodes, respectively. The SDCM in this configuration can be directly pressed on the working electrode surface (the glass substrate covered with the evaporated alloy library) in contact mode. The contact area $\left(0.0490 \mathrm{~cm}^{2}\right)$ of SDCM was carefully measured under a scanning electron microscope by examining the anodized spot size.

Open circuit potential (OCP) values were recorded for $300 \mathrm{~s}$ from Al-1.5 at.\% Ce to Al-10.5 at.\% Ce at 15 different locations (Fig. $1 b)$. Following OCP recording, potentiodynamic polarization was locally performed on a given alloy composition with a stepwise potential increase of $1 \mathrm{~V}$ to a maximum of $10 \mathrm{~V}$ at a sweep rate of $100 \mathrm{mV} \mathrm{s}^{-1}$ in a $0.2 \mathrm{M}$ phosphate buffer ( $\mathrm{pH}$ 8.3). The SDCM movement in xyz directions at different locations is controlled by a selfdeveloped Labview program and it enables to address in an automated manner the different compositions along the library. All potentials are referred to the standard hydrogen electrode (SHE). The phosphate buffer was prepared by mixing $0.2 \mathrm{M}$ anhydrous potassium phosphate monobasic and $0.2 \mathrm{M}$ sodium phosphate dibasic heptahydrate in such a way to obtain a final $\mathrm{pH}$ of 8.3. Film resistance and dielectric properties were determined by simultaneously coupling EIS with potential sweep measurements using a Compact Stat electrochemical interface system (IVIUM Technology) with an AC amplitude of $50 \mathrm{mV}$ in a frequency range of $10^{5}$ to $10^{-1} \mathrm{~Hz}$. A detailed description of the experimental sequence can be found elsewhere [35]. The present study was conducted using a stagnanttype SDCM. The fresh electrolyte was pumped inside the SDCM to make a contact with the film surface at a given alloy composition and it remained in contact with the resulting film surface during the complete CV-EIS study. Afterward, the electrolyte was pumped out before SDCM moved to a next position. In this way, each alloy composition was exposed to fresh electrolyte prior to investigation. The online detailed analysis of electrolyte by ICP-MS and ICP-OES is a promising approach in corrosion processes and allows us to differentiate elemental dissolution from other reactions such as oxygen gas evolution $[40,41]$. However, in this study, the online analysis is not employed owing to the possibility of a negligible concentration of total dissolved solids (TDS) at $\sim 100 \%$ Faradaic efficiency. The thermodynamic information and electro-

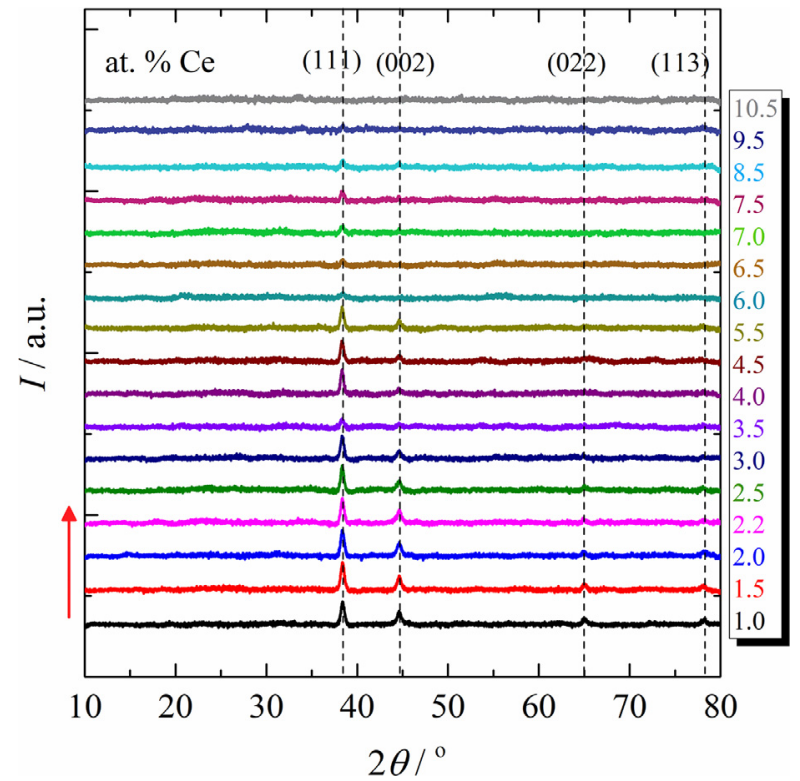

Fig. 2. XRD pattern of thermally evaporated Al-Ce thin film alloys.

chemical reactions (Table 1) used for simulations were taken from the Pourbaix atlas [42], Geochemist's workbench [43, 44], FACTSAGE [45], and Medusa database [46,47]. Solid-aqueous reaction energies were also computed with the aid of Python programming and Pymatgen module using open source web application [48]. The Eh-pH diagrams from first-principles DFT calculations are constructed from the high-throughput infrastructure developed by Jain et al. and his co-workers [49,50], where experimentally determined free energies of aqueous ions and calculated DFT energies for solid phases are used to construct multi-element compositional phase diagrams. Then these compositional phase diagrams are used to plot Eh-pH diagrams. All Eh-pH plots were simulated at $298 \mathrm{~K}$ and atmospheric pressure.

\section{Results and discussion}

\subsection{Film structure and morphology}

The details of crystallographic phases of individual alloys were investigated in both $\theta-2 \theta$ and $\omega-2 \theta$ modes at different positions along the Al-Ce alloy library ranging from $\mathrm{Al}-1$ at.\% Ce to Al-10.5 at.\%. Fig. 2 shows the XRD patterns as a function of Ce concentration. Higher peaks intensities of typical fcc Al phase (111) are evidenced at low Ce contents. Careful examination of the XRD pattern indicates that high peak intensity maintained until Al-5.5 at.\% Ce and thereafter, the peak intensity sharply decreases to lower value and disappeared completely at 10.5 at.\% Ce. As reported for another Al-RE system [33], a slight shift of the fcc-Al(111) started to be visible only at Er concentration higher than 15 at.\% and no apparent peak shift was observable below this concentration. Similarly, a visible peak shift was not observed in the Al-Ce system within the studied concentrations. Due to the similar properties of REEs, a direct comparison between the two systems can be made, since the atomic radii of the REEs replacing the $\mathrm{Al}$ (143 pm), namely $\mathrm{Er}(232 \mathrm{pm})$ and $\mathrm{Ce}(248 \mathrm{pm})$ are very similar. The reduction in peak intensity can be associated with a loss of crystallinity suggesting a strong influence of Ce concentration on Al-Ce alloys. Detailed examination of binary Al-RE systems predicted by Gschneidner et al. reveals that $\mathrm{REAl}_{3}$ tri-aluminide intermetallic is generally formed when the lanthanoids structure changes from predominantly hexagonal to cubic, due to the reduction of radius ratio be- 
Table 1

Literature survey of important chemical and electrochemical reactions and standard Gibbs free energies of formation for selected systems.

\begin{tabular}{|c|c|c|c|}
\hline \multirow{2}{*}{$\begin{array}{l}\text { Chemical and electrochemical reactions } \\
\mathbf{H}_{2} \mathbf{O}\end{array}$} & \multicolumn{2}{|c|}{$\Delta G\left(\mathrm{~kJ} \mathrm{~mol}{ }^{-1}\right)$ Species } & \multirow{2}{*}{$\Delta G_{f}^{0}\left(\mathrm{~kJ} \mathrm{~mol}{ }^{-1}\right)$} \\
\hline & & & \\
\hline $2 \mathrm{H}_{2} \mathrm{O}_{(\mathrm{l})} \rightarrow 4 \mathrm{H}^{+}+4 \mathrm{e}^{-}+\mathrm{O}_{2}(\mathrm{~g})$ & 474.27 & $\mathrm{H}_{2} \mathrm{O}$ & -237.30 \\
\hline \multicolumn{4}{|l|}{$\mathrm{Ce}-\mathrm{H}_{2} \mathrm{O}$ system } \\
\hline $\mathrm{Ce}^{3+}+3 \mathrm{e}^{-} \rightarrow \mathrm{Ce}$ & 677.06 & $\mathrm{Ce}^{3+}$ & -677.06 \\
\hline $\mathrm{Ce}^{3+}+3 \mathrm{H}_{2} \mathrm{O} \rightarrow 3 \mathrm{H}^{+}+\mathrm{Ce}(\mathrm{OH})_{3}(\mathrm{~s})$ & 113.55 & $\mathrm{Ce}(\mathrm{OH})_{3}(\mathrm{~s})$ & -1275.60 \\
\hline $\mathrm{Ce}^{3+}+2 \mathrm{H}_{2} \mathrm{O} \rightarrow 4 \mathrm{H}^{+}+\mathrm{Ce}(\mathrm{OH})_{4}^{-}$ & 220.81 & $\mathrm{Ce}(\mathrm{OH})_{4}^{-}$ & -930.99 \\
\hline $2 \mathrm{Ce}^{3+}+2 \mathrm{H}_{2} \mathrm{O} \rightarrow \mathrm{CeO}_{2}+4 \mathrm{H}^{+}+e^{-}$ & 121.30 & $\mathrm{CeO}_{2}$ & -1030.5 \\
\hline $2 \mathrm{Ce}^{3+}+2 \mathrm{H}_{2} \mathrm{O} \rightarrow \mathrm{Ce}(\mathrm{OH})_{2}^{+}+2 \mathrm{H}^{+}$ & 96.46 & $\mathrm{Ce}(\mathrm{OH})_{2}{ }^{+}$ & -1058.34 \\
\hline $2 \mathrm{Ce}^{3+}+3 \mathrm{H}_{2} \mathrm{O} \rightarrow \mathrm{Ce}_{2} \mathrm{O}_{3}+6 \mathrm{H}^{+}$ & 356.67 & $\mathrm{Ce}_{2} \mathrm{O}_{3}$ & -1709.65 \\
\hline \multicolumn{4}{|l|}{ Ce- $\mathrm{H}_{2}$ 0-0.1 M Cit-0.2 M Phosphate system } \\
\hline $\mathrm{Cit}^{3-}+\mathrm{Ce}^{3+} \rightarrow \mathrm{Ce}(\mathrm{cit})$ & -53.64 & $\mathrm{Ce}($ cit $)$ & -1892.50 \\
\hline $2 \mathrm{H}^{+}+\mathrm{Ce}^{3+}+\mathrm{PO}_{4}^{3-} \rightarrow \mathrm{CeH}_{2} \mathrm{PO}_{4}{ }^{2+}$ & -126.46 & $\mathrm{CeH}_{2} \mathrm{PO}_{4}^{2+}$ & -1828.22 \\
\hline $\mathrm{Ce}^{3+}+\mathrm{PO}_{4}^{3-} \rightarrow \mathrm{CePO}_{4}(\mathrm{~s})$ & -149.90 & $\mathrm{CePO}_{4}(\mathrm{~s})$ & -1851.67 \\
\hline \multicolumn{4}{|l|}{ Ce- $\mathrm{H}_{2}$ 0-0.1 M F system } \\
\hline $3 \mathrm{~F}-+\mathrm{Ce}^{3+}+0.5 \mathrm{H}_{2} \mathrm{O}^{-} \rightarrow \mathrm{CeF}_{3}: 0 \bullet 5 \mathrm{H}_{2} \mathrm{O}$ & -107.3 & $\mathrm{CeF}_{3}: 0 \bullet 5 \mathrm{H}_{2} \mathrm{O}$ & -1739.50 \\
\hline \multicolumn{4}{|l|}{ Ce- $\mathrm{H}_{2}$ O- 0.2 M Phosphate system } \\
\hline $\mathrm{Ce}^{3+}+\mathrm{PO}_{4}^{3-} \rightarrow \mathrm{CePO}_{4}(\mathrm{~s})$ & -149.90 & $\mathrm{CePO}_{4}(\mathrm{~s})$ & -1851.67 \\
\hline \multicolumn{4}{|l|}{ Borate- $\mathrm{H}_{2} \mathrm{O}$ system } \\
\hline $2 \mathrm{~B}(\mathrm{OH})_{3} \rightarrow \mathrm{B}_{2} \mathrm{O}_{3}(\mathrm{cr})+3 \mathrm{H}_{2} \mathrm{O}$ & 32.78 & $\mathrm{~B}_{2} \mathrm{O}_{3}(\mathrm{cr})$ & -1194.79 \\
\hline $\mathrm{H}_{3} \mathrm{BO}_{3}(\mathrm{~s}) \rightarrow \mathrm{B}(\mathrm{OH})_{3}$ & 0.40 & $\mathrm{H}_{3} \mathrm{BO}_{3}(\mathrm{~s})$ & -969.440 \\
\hline \multicolumn{4}{|l|}{ Citrate- $\mathrm{H}_{2} \mathrm{O}$ system } \\
\hline & & $\mathrm{Cit}^{3-}{ }_{(\mathrm{aq})}$ & -1161.80 \\
\hline $\mathrm{H}^{+}+\mathrm{Cit}^{3-} \mathrm{CH}(\mathrm{Cit})^{2-}$ & -36.50 & $\mathrm{H}(\mathrm{Cit})^{2-}$ & -1198.30 \\
\hline $2 \mathrm{H}^{+}+\mathrm{Cit}^{3-} \rightarrow \mathrm{H}_{2}(\mathrm{Cit})^{-}$ & -63.66 & $\mathrm{H}_{2}(\mathrm{Cit})^{-}$ & -1225.46 \\
\hline $3 \mathrm{H}^{+}+\mathrm{Cit}^{3-} \rightarrow \mathrm{H}_{3}(\mathrm{Cit})$ & -81.51 & $\mathrm{H}_{3}$ (Cit) & -1243.31 \\
\hline \multicolumn{4}{|l|}{ Ce- $\mathrm{H}_{2}$ 0-0.1 M Acetate system } \\
\hline $\mathrm{Ce}^{3+}+\mathrm{CH}_{3} \mathrm{COO}^{-} \rightarrow \mathrm{Ce}\left(\mathrm{CH}_{3} \mathrm{CHOO}\right)^{2+}$ & -3.52 & $\left.\mathrm{Ce}\left(\mathrm{CH}_{3} \mathrm{COO}\right)^{2+}{ }_{\text {(aq. }}\right)$ & -1050.04 \\
\hline $\mathrm{Ce}^{3+}+2 \mathrm{CH}_{3} \mathrm{COO}^{-} \rightarrow \mathrm{Ce}\left(\mathrm{CH}_{3} \mathrm{CHOO}\right)_{2}{ }^{+}$ & -5.74 & $\mathrm{Ce}\left(\mathrm{CH}_{3} \mathrm{COO}\right)_{2}+($ aq. $)$ & -1421.60 \\
\hline $\mathrm{Ce}^{3+}+3 \mathrm{CH} 3 \mathrm{COO}^{-} \rightarrow \mathrm{Ce}\left(\mathrm{CH}_{3} \mathrm{CHOO}\right)_{3}$ & -6.86 & $\mathrm{Ce}\left(\mathrm{CH}_{3} \mathrm{COO}\right)_{3}$ (aq.) & -1792.12 \\
\hline \multicolumn{4}{|l|}{$\mathrm{P}-\mathrm{H}_{2} \mathrm{O}$ system } \\
\hline $\mathrm{P}(\mathrm{cr})+4 \mathrm{H}_{2} \mathrm{O} \rightarrow 8 \mathrm{H}^{+}+5 \mathrm{e}^{-}+\mathrm{PO}_{4}^{3-}$ & -75.26 & $\mathrm{PO}_{4}{ }^{3-}$ & -1024.74 \\
\hline $11 \mathrm{H}^{+}+8 \mathrm{e}^{-}+\mathrm{PO}_{4}^{3-} \rightarrow \mathrm{PH}_{3}(\mathrm{aq})$ & -44.84 & $\mathrm{PH}_{3}$ & -120.0 \\
\hline \multicolumn{4}{|l|}{$\mathrm{Al}-\mathrm{H}_{2} \mathrm{O}$ system } \\
\hline $3 \mathrm{e}^{-}+\mathrm{Al}^{3+} \rightarrow \mathrm{Al}(\mathrm{s})$ & 481.0 & $\mathrm{Al}^{3+}$ & -481.0 \\
\hline $\mathrm{Al}^{3+}+3 \mathrm{H}_{2} \mathrm{O} \rightarrow 3 \mathrm{H}^{+}+\mathrm{Al}(\mathrm{OH})_{3}(\mathrm{~s})$ & 59.23 & $\mathrm{Al}(\mathrm{OH})_{3}(\mathrm{~s})$ & -1137.6 \\
\hline $\mathrm{Al}^{3+}+4 \mathrm{H}_{2} \mathrm{O} \rightarrow 4 \mathrm{H}^{+}+\mathrm{Al}(\mathrm{OH})_{4}^{-}$ & 129.52 & $\mathrm{Al}(\mathrm{OH})_{4}^{-}$ & -310.92 \\
\hline $2 \mathrm{Al}^{3+}+3 \mathrm{H}_{2} \mathrm{O} \rightarrow \mathrm{Al}_{2} \mathrm{O}_{3}+6 \mathrm{H}^{+}$ & 91.81 & $\mathrm{Al}_{2} \mathrm{O}_{3}$ & -1582.3 \\
\hline $\mathrm{Al}+3 \mathrm{H}_{2} \mathrm{O} \rightarrow \mathrm{Al}_{2} \mathrm{O}_{3}+6 \mathrm{H}^{+}+6 \mathrm{e}^{-}$ & 152.51 & & \\
\hline \multicolumn{4}{|l|}{ Al- $\mathrm{H}_{2} \mathrm{O}$-Phosphate system } \\
\hline $\mathrm{AlHPO}_{4}^{+} \rightarrow \mathrm{Al}^{3+}+\mathrm{H}^{+}+\mathrm{PO}_{4}^{3-}$ & 49.576 & $\mathrm{AlHPO}_{4}^{+}$ & -1555.34 \\
\hline $\mathrm{Al}_{2} \mathrm{PO}_{4}^{3+} \rightarrow 2 \mathrm{Al}^{3+}+\mathrm{PO}_{4}^{3-}$ & 47.020 & $\mathrm{Al}_{2} \mathrm{PO}_{4}{ }^{3+}$ & -2033.78 \\
\hline $\mathrm{Al}^{3+}+\mathrm{PO}_{4}^{3-} \rightarrow \mathrm{AlPO}_{4}$ & 112.16 & $\mathrm{AlPO}_{4}$ & -1617.90 \\
\hline
\end{tabular}

Table 2

Average grain size for Al-Ce alloys.

\begin{tabular}{llllllllll}
\hline Alloy Composition /at.\% Ce & 1.0 & 2.0 & 3.0 & 4.0 & 5.5 & 6.5 & 8.5 & 9.5 & 10.5 \\
Average Grain size / nm & 91 & 95 & 93 & 89 & 102 & 120 & 118 & 106 & 85 \\
\hline
\end{tabular}

tween $\mathrm{Al}$ and lanthanoid and the first four members of lanthanoids ( $\mathrm{La}, \mathrm{Ce}, \mathrm{Nd}, \mathrm{Pr}$ ) form the compound $\mathrm{RE}_{3} \mathrm{Al}_{11}$ as the Al-rich phase [51]. Contrary to binary Al-Ce phase diagram, the existence of $\mathrm{Al}$ and $\alpha-\mathrm{Ce}_{3} \mathrm{Al}_{11}$ intermetallic mixture has not been observed for a compositional spread of 1.5 to 10.5 at.\% Ce [52]. There might be a possibility that the concentration of $\mathrm{Al}$ rich-phase predominates in the alloy crystal matrix and significantly overshadows the presence of $\alpha-\mathrm{Ce}_{3} \mathrm{Al}_{11}$. The remarkable loss in crystallinity and amorphization was only evident at higher concentration of $\mathrm{RE}$ into the $\mathrm{Al}$ matrix [53]. The amorphization may be associated with the large difference in atomic radii of $\mathrm{Al}$ and $\mathrm{RE}$ atoms. Therefore, it is inferred that low concentration of Ce into the Al matrix may produce a mixture of $\mathrm{Al}$ and intermetallic instead of yielding $\mathrm{Al}$ and amorphous phase. Morphological features on the film surface along the Al-Ce compositional spreads before and after electrochemical studies were examined by SEM. A set of Al-Ce alloys is presented in Fig. 3 and the average grain size as a function of Ce concentration for various alloys is given in Table 2. The grain size was determined from SEM images by taking average of 20 grains at different positions using image J software. The microstructural analysis shows a gradual change in surface morphology with increasing Ce concentration as shown in the upper left corner of each figure. The drastic change in surface morphology is only evident at 10.5 at.\% Ce and characteristic Al grains can be readily observed until 9.5 at.\% Ce. The distinct morphology can be clearly seen at 10.5 at.\% Ce. Reduction in characteristic Al grains size might be responsible for the vanishing of $\mathrm{Al}$ peak at 10.5 at.\% Ce in XRD analysis. Generally, Al anodizing at $100 \%$ Faradaic efficiency induces smooth surface for thicker films. Surface smoothening is not evident in SEM examination after anodizing Al-Ce library and surface morphologies did not show any significant change before and after oxidation. In other words, anodized surface morphologies can be easily controlled by the texture of the original parent surface for few nanometer-thin films. Furthermore, the tunnelling of secondary electrons during 

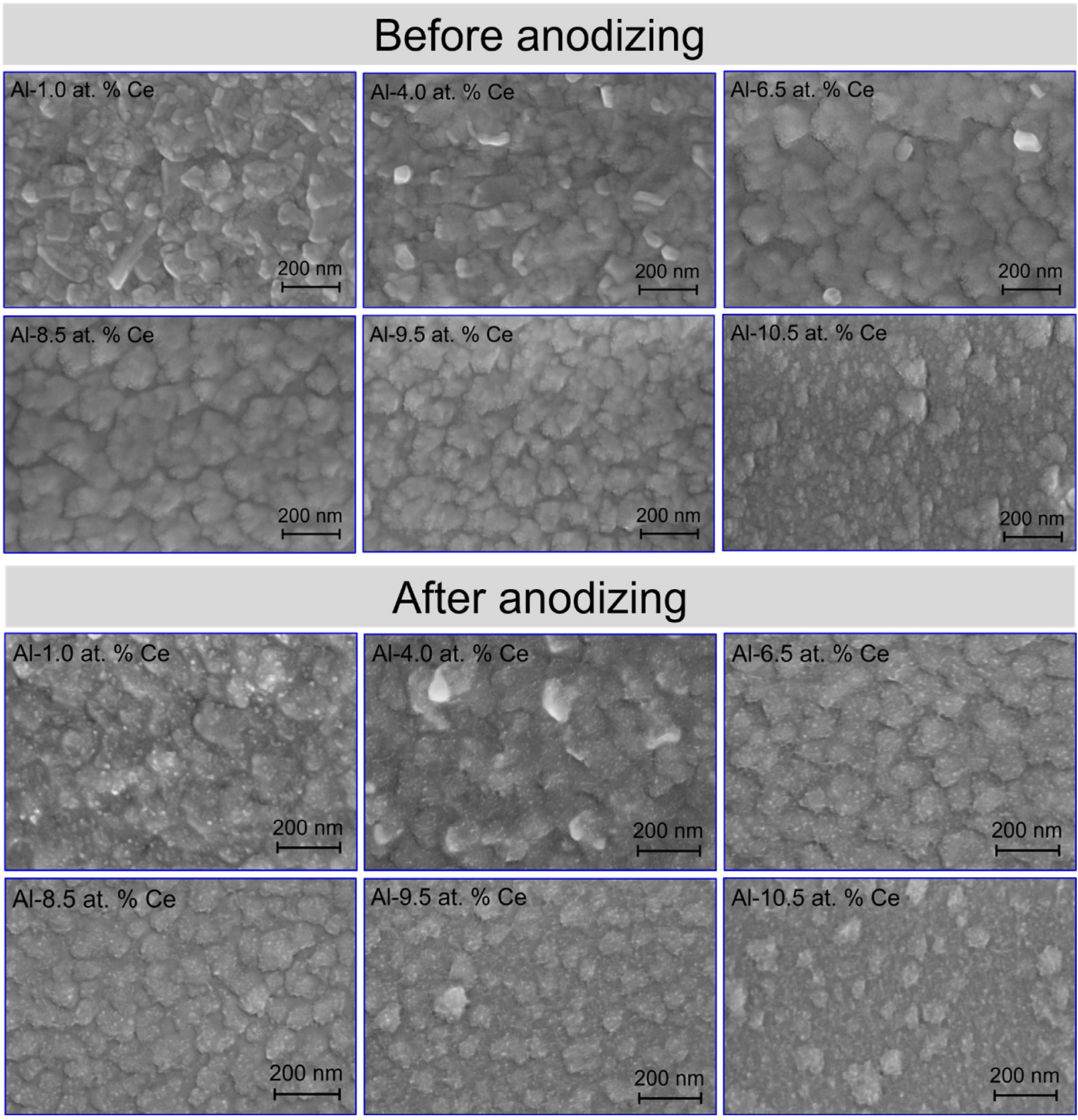

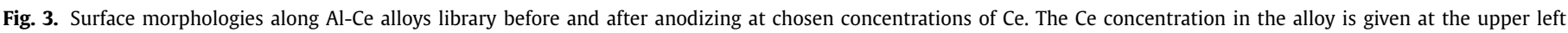
corner of each figure.

SEM image acquisition cannot be overlooked at low potential anodizing. Despite these identical images, the presence of phosphate precipitates in the form of small white spots can be observed in the anodic film, indicating strong phosphate adsorption on the metal-oxide surface. It is likely that strong complexing power of phosphate towards RE cations (Ce in the present case), may inhibit the dissolution of film materials as RE phosphates are highly insoluble in aqueous electrolytes [54]. Nevertheless, no signs of localized corrosion or pitting have been found on film surface.

\subsection{Electrochemical studies}

Composition and structural complexity in binary Al-RE alloys of relatively large atomic mismatch renders the measurement unstable $[33,53]$. The dissolution and formation of the protective film depend primarily on $\mathrm{pH}$ of the electrolyte. One alloy constituent may dissolve easily in alkaline conditions compared with other. Moreover, structure and morphological complexity induced by lattice mismatch and the large difference in atomic radii of individual constituents may enhance the dissolution susceptibility of metal under given condition. The transient species and metastable phases, which may play a crucial role in film formation are often overlooked. These species may influence the structure and chemistry of the resulting films. The conventional Pourbaix diagrams are still extensively used to evaluate stability regions of materials under varying conditions of potential and $\mathrm{pH}$ in aqueous environments. Unfortunately, the known Eh-pH or Pourbaix diagrams provide thermodynamic information only for the metal- $\mathrm{H}_{2} \mathrm{O}$ systems, consequently, identification of compromise $\mathrm{pH}$ range allowing simultaneous oxidation of multi-elements in an alloy is still not clear so far. This in turns limits the electrolyte selection as well as the expansion of potential applications of many alloy sys- 

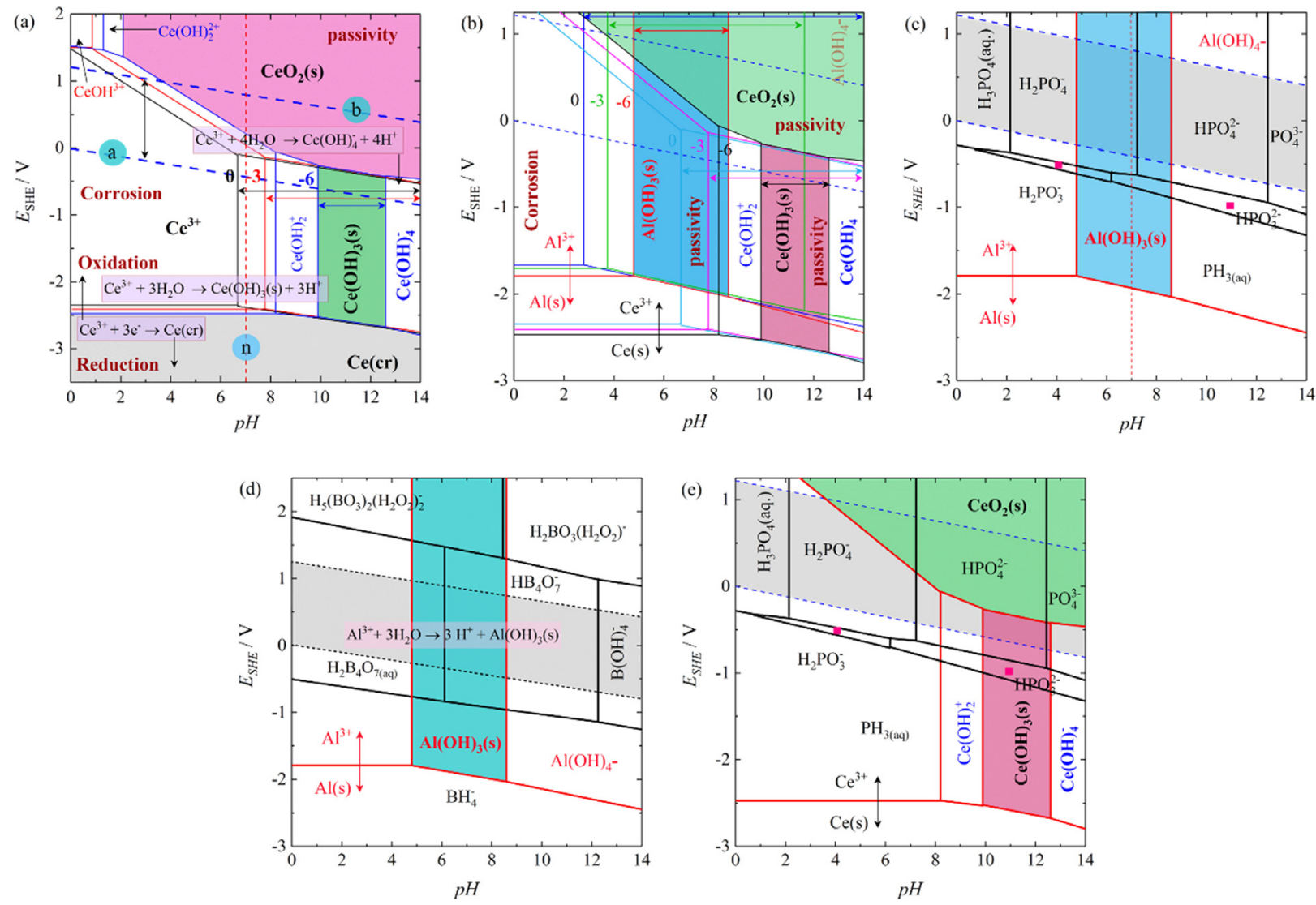

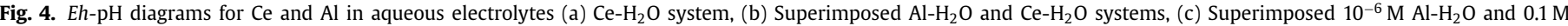

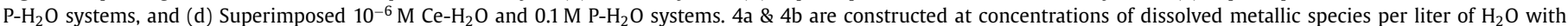
exponents $0,-3$, and -6 as indicated by different coloured lines. The diagrams are constructed at $298 \mathrm{~K}$.

tems [42, 55-56]. As a result, a large amount of previously reported thermodynamic data is collected and modification in existing Eh-pH diagrams are performed through different simulation softwares and DFT computations to obtain realistic information [49]. The complexity of multi-component systems makes it very difficult to simulate Eh-pH diagrams and it is even more challenging to generate these diagrams from experiments. The determination of Pourbaix diagrams from experiments is very tricky, tedious, and meticulous task, as the information of both aqueous ions and solid phases is needed to establish electrochemical phase equilibria. Superimposition and simulations of these diagrams from commercial softwares and first-principles DFT calculations can quickly generate $E h$-pH diagrams of multi-elements or complex systems in a high-throughput manner. As an example, Fig. 4 shows the simulated Eh-pH diagrams of $\mathrm{Al}$ and Ce either in water or in presence of oxide-forming substances such as phosphate. Oxides/hydroxides of RE are generally soluble in acidic solutions and relatively stable in the alkaline environment. The $\mathrm{Ce}_{2} \mathrm{O}_{3} / \mathrm{CeO}_{2} / \mathrm{Ce}(\mathrm{OH})_{3}$ is also unstable in acidic solutions as can be seen from the Eh-pH response of $\mathrm{Ce}$ in $\mathrm{Ce}-\mathrm{H}_{2} \mathrm{O}$ system at different concentrations of dissolved Ce (Fig. 4a). Al exhibits trivalent ionic state as the stable state in aqueous electrolyte, while Ce displays $\mathrm{Ce}^{3+}$ and $\mathrm{Ce}^{4+}$ ionic states as the stable state. Both elements can form stable oxide in the presence of oxygen. Due to more negative free energies of oxides (Table 1), the $\mathrm{Al}(\mathrm{OH})_{3}$ and $\mathrm{Ce}(\mathrm{OH})_{3}$ will eventually transform to $\mathrm{Ce}_{2} \mathrm{O}_{3}$ and $\mathrm{Al}_{2} \mathrm{O}_{3}$. $\mathrm{Ce}(\mathrm{OH})_{3}$ stability domain moves to $\mathrm{pH} 10$ at $10^{-6} \mathrm{M} \mathrm{L}^{-1}$ concentration of $\mathrm{Ce}$ in the electrolyte, indicating that negligible dissolution of $\mathrm{Ce}$ at $\sim$ higher growth efficiency is feasible around $\mathrm{pH} 10$. On the other hand, the stability of $\mathrm{Al}(\mathrm{OH})_{3}$ terminates around $\mathrm{pH} 8.6$ at this concentration. Therefore, it is ther- modynamically a tedious effort to form stable films on Al-Ce alloys with individual oxide/hydroxide having different susceptibilities of dissolution in respective $\mathrm{pH}$ domains. This was clearly observed from the superimposed Eh-pH diagrams of $\mathrm{Al}$ and $\mathrm{Ce}$ in water (Fig. 4b), where both elements have different $\mathrm{pH}$ range for oxidation. Now the question arises, how to modify the Eh-pH diagrams of $\mathrm{Al}-\mathrm{H}_{2} \mathrm{O}$ and $\mathrm{Ce}-\mathrm{H}_{2} \mathrm{O}$ systems to find a compromise $\mathrm{pH}$ range. A common approach is the addition of oxide-forming substances such as phosphate, borate, citrate, tartrate, malonate etc. into the aqueous electrolyte to reduce the activity of dissolving metals into the solution. It is expected that addition of these substances must modify the thermodynamic stability domains as well as the domains of relative predominance of the dissolved species. Therefore, the realistic effect of the various oxide-forming substances on $\mathrm{Al}-\mathrm{H}_{2} \mathrm{O}$ and $\mathrm{Ce}-\mathrm{H}_{2} \mathrm{O}$ systems was predicted in two different ways. In the first approach, superimposition of metal- $\mathrm{H}_{2} \mathrm{O}$ and complex forming element- $\mathrm{H}_{2} \mathrm{O}$ systems (such as $\mathrm{Al}-\mathrm{H}_{2} \mathrm{O}-\mathrm{P}$ and $\mathrm{Ce}-\mathrm{H}_{2} \mathrm{O}-\mathrm{P}$ systems) can provide an approximate guess for common oxidation as in Fig. 4c-d. It was then realized that such superimposition do not alters the Eh-pH diagrams of either metal owing to the absence of actual equilibrium reactions of the metal- $\mathrm{H}_{2} \mathrm{O}$ system in the presence of these substances (Fig. 4c-d). As a second approach, simulation of $E h-p H$ plots by considering all possible thermodynamic reactions provide a more accurate guess for $\mathrm{pH}$ range and electrolyte selection prior to oxidation. Hence, we further analysed the $\mathrm{Al}-\mathrm{H}_{2} \mathrm{O}$ and $\mathrm{Ce}-\mathrm{H}_{2} \mathrm{O}$ systems by means of commercially available simulation softwares including a first-principle DFT computation method recently proposed by Persson et al. [49]. A few examples of these calculations in Fig. 5a-d reveal the notable change in Eh-pH plots of $10^{-6} \mathrm{M} \mathrm{Al}-0.1 \mathrm{M} \mathrm{P}-\mathrm{H}_{2} \mathrm{O}$ system (Fig. 5a), 

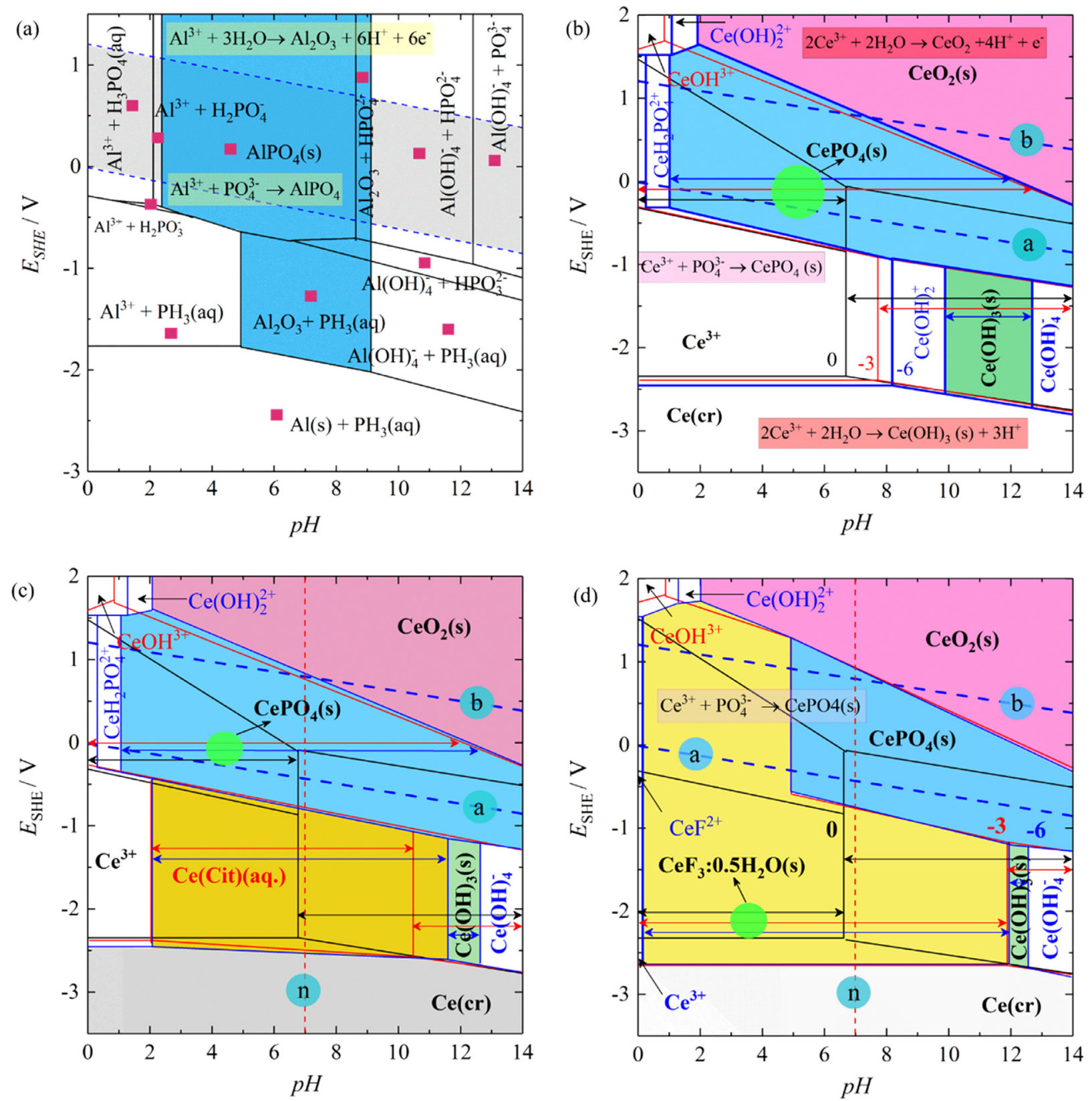

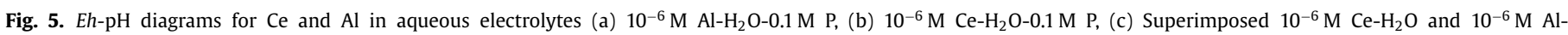

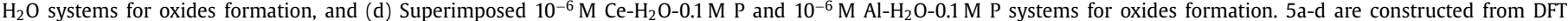
computations at $298 \mathrm{~K}$ and Figs. $5 \mathrm{c}-\mathrm{d}$ are computed for 89 at.\% $\mathrm{Al}$ and 11 at.\% Ce alloy.

$10^{-6} \mathrm{M}$ Ce-0.1 M P- $\mathrm{H}_{2} \mathrm{O}$ system (Fig. 5b), and superimposed $10^{-6} \mathrm{M}$ $\mathrm{Ce}-\mathrm{H}_{2} \mathrm{O}-0.1 \mathrm{M} \mathrm{P}$ and $10^{-6} \mathrm{M}$ Al- $\mathrm{H}_{2} \mathrm{O}-0.1 \mathrm{M}$ P systems (Fig. 5d). The summary of formation energies of additional reactions is presented in Table 3. From Fig. 5a and b, it is obvious that phosphate incorporation remarkably modifies the Eh-pH diagrams of both the constituents of the alloy. In comparison with Fig. 4, the stability window for $\mathrm{H}_{2} \mathrm{O}$ is completely covered with phosphate-containing species such as $\mathrm{AlPO}_{4}$ and $\mathrm{CePO}_{4}$ between $\mathrm{pH}$ 5-9. Thereby, superimposition of Al-P- $\mathrm{H}_{2} \mathrm{O}$ and $\mathrm{Ce}-\mathrm{P}-\mathrm{H}_{2} \mathrm{O}$ systems (Fig. 5d) can effectively provide a compromise $\mathrm{pH}$ range between $5.0-9.0$ for simultaneous oxidation of both $\mathrm{Al}$ and $\mathrm{Ce}$ in phosphate-containing electrolytes or other electrolytes that can meet the thermodynamic criteria. On the other hand, merging only $\mathrm{Al}-\mathrm{H}_{2} \mathrm{O}$ and $\mathrm{Ce}-\mathrm{H}_{2} \mathrm{O}$ systems for oxides (Fig. 5c) and hydroxides (Fig. 4b) formation do not provide the answer on thermodynamic basis for combined oxida-
Table 3

Standard enthalpy of formation of selected reactions from DFT calculations.

\begin{tabular}{llll}
\hline Chemical reactions & $\Delta H_{R}\left(\mathrm{~kJ} \mathrm{~mol}^{-1}\right)$ & Species & $\Delta H_{f}^{O}\left(\mathrm{~kJ} \mathrm{~mol}^{-1}\right)$ \\
\hline $\mathrm{Ce}+2 \mathrm{O}_{2}+\mathrm{P} \rightarrow \mathrm{CePO}_{4}$ & -1975 & $\mathrm{CePO}_{4}$ & -1975 \\
$\mathrm{Al}+2 \mathrm{O}_{2}+\mathrm{P} \rightarrow \mathrm{AlPO}_{4}$ & -1733 & $\mathrm{AlPO}_{4}$ & -1733 \\
$4 \mathrm{Ce}+3 \mathrm{O}_{2} \rightarrow 2 \mathrm{Ce}_{2} \mathrm{O}_{3}$ & -3600 & $\mathrm{Ce}_{2} \mathrm{O}_{3}$ & -1800 \\
$\mathrm{Ce}+\mathrm{O}_{2} \rightarrow \mathrm{CeO}_{2}$ & -1090 & $\mathrm{CeO}_{2}$ & -1090 \\
$\mathrm{O}_{2}+2 \mathrm{Ce}_{2} \mathrm{O}_{3} \rightarrow 4 \mathrm{CeO}_{2}$ & -762 & - & - \\
$4 \mathrm{Al}+3 \mathrm{O}_{2} \rightarrow 2 \mathrm{Al}_{2} \mathrm{O}_{3}$ & -3351 & $\mathrm{Al}_{2} \mathrm{O}_{3}$ & -1675 \\
$2 \mathrm{Ce}+2 \mathrm{Al}+3 \mathrm{O}_{2} \rightarrow 2 \mathrm{CeAlO}_{3}$ & -3602 & $\mathrm{CeAlO}_{3}$ & -1801 \\
$\mathrm{Ce}+\mathrm{H}_{2} \rightarrow \mathrm{CeH}_{2}$ & -193.0 & $\mathrm{CeH}_{2}$ & -193.0 \\
\hline
\end{tabular}

tion of both $\mathrm{Al}$ and Ce. For instance, between the $\mathrm{pH}$ 5.0-9.0, neither the stability window of $\mathrm{H}_{2} \mathrm{O}$ has complete protection, nor the 


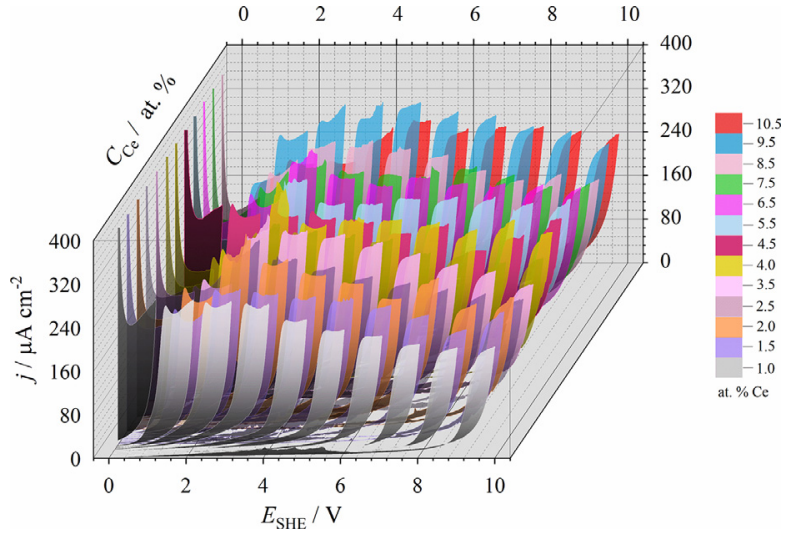

Fig. 6. Cyclic voltammograms at different concentration of $\mathrm{Ce}$ along the $\mathrm{Al}-\mathrm{Ce} \mathrm{li}-$ brary. Each single alloy composition was electrochemically scanned in phosphate buffer ( $\mathrm{pH}$ 8.3) from $0 \mathrm{~V}$ to a maximum of $10 \mathrm{~V}$ and then scanned back to $0 \mathrm{~V}$. The potential was stepwise increased with $1 \mathrm{~V}$ increment.

$\mathrm{Ce}^{3+}$ species is inhibited from active dissolution. Therefore, a complete understanding of Eh-pH diagrams of alloy anodizing is crucial for accurate prediction of $\mathrm{pH}$ range and electrolyte selection. This approach will not only modify the Eh-pH diagrams for each metal either by inhibition of metal cations dissolution or by the formation of more stable substances but will also provide a rapid prediction of common electrolyte selection. After careful examination of Eh-pH diagrams and reactions energies (Table 1 and 3), $0.2 \mathrm{M}$ phosphate buffer having $\mathrm{pH} 8.3$ is selected for polarization studies of Al-Ce alloys as $\mathrm{AlPO}_{4}$ and $\mathrm{CePO}_{4}$ offer relatively high negative free energies ( -1617.90 and $-1851.67 \mathrm{~kJ} \mathrm{~mol}^{-1}$, respectively) in different simulated systems as well as provide complete protection of the $\mathrm{H}_{2} \mathrm{O}$ stability window in near neutral electrolyte. It is worth mentioning to explain here that DFT computations were performed to maximize any metastable, stable or unstable phase prediction in solid-aqueous equilibria and to accurately obtain the $\Delta G_{f}$ and $\Delta H_{f}$ values. For example, presence of $\mathrm{AlPO}_{4}, \mathrm{CePO}_{4}$, and $\mathrm{CeH}_{2}$ (Fig. 5) can not be prophesied without considering the compositional phase diagrams (as will be shown later in Fig. 7).

\subsection{Potentiodynamic anodizing and characterization}

Following electrolyte selection, combined step-wise potentiodynamic anodizing and EIS studies of resulting mixed anodic films were performed on selected surfaces using the SDCM. Series of cyclic voltammograms were recorded at 15 different locations by positioning the tip of the SDCM along the Al-Ce compositional spread. Prior to film formation on each alloy, OCP measurement was conducted (Fig. 1c). The identical OCPs at different positions of the library show the nearly identical surface potential. SEM surface features and Al peaks in XRD analysis indicate that the addition of Ce should not induce remarkably different surface energies. A complete graphical representation of CVs is presented in Fig. 6 for potential variation between 1 and $10 \mathrm{~V}$ (versus SHE). This corresponds to 150 potentiodynamic scans and EIS spectra. In agreement with SEM and XRD, the similar CV response typical of Al anodizing is obtained. The valve metal characteristics can be readily observed upon reversal of potential scan after $1 \mathrm{~V}$ step. This indicates that typical passive films characteristics can be obtained in Al-Ce alloys with a higher additional strength from Ce addition. The higher strength due to Ce addition is justifiable from the fundamental point of view, when an element of higher melting point $(1072 \mathrm{~K}$ for $\mathrm{Ce})$ and density $\left(6.76 \mathrm{~g} \mathrm{~cm}^{-3}\right.$ for $\left.\mathrm{Ce}\right)$ is introduced into the host element of relatively lower melting point ( $933 \mathrm{~K}$ for $\mathrm{Al}$ ) and density $\left(2.71 \mathrm{~g} \mathrm{~cm}^{-3}\right.$ for $\left.\mathrm{Al}\right)$, the strength of alloys generally increases. The effect can be enhanced when a heavier element having large atomic radii, Ce $(248 \mathrm{pm})$ in the present case is alloyed with an element of lower atomic radii such as $\mathrm{Al}(143 \mathrm{pm})$. Likewise, the $\mathrm{Ce}_{2} \mathrm{O}_{3}$ and $\mathrm{CeO}_{2}$ have higher melting points $(2450 \mathrm{~K}$ and $2673 \mathrm{~K}$ respectively) compared with the $\mathrm{Al}_{2} \mathrm{O}_{3}(2345 \mathrm{~K})$. Our literature survey shows that the addition of $\mathrm{Ce}$ into the $\mathrm{Al}$ and $\mathrm{CeO}_{2}$ in the $\mathrm{Al}_{2} \mathrm{O}_{3}$ matrix increases the strength and mechanical properties [57,58], even though mechanical properties enhancement of $\mathrm{Al}_{2} \mathrm{O}_{3}$ by $\mathrm{CeO}_{2}$ addition also depends on post anodizing heat treatments and other factors in particular the distribution of the second phase.

This example shows the obvious advantage of combinatorial investigations over common batch sample analysis. As long as there is no drastic change in behavior in which a certain alloy shows reduction in property, there would be a valid reason to continue with further addition of a mismatching element to explore new applications resulting from additional strength of the second element. Equal treatment of different alloy compositions, in particular the preparation history, aging, air-exposure provides an additional advantage to the combinatorial approach as a small difference in properties would be associated with the change in composition. Considering the sesquioxide nature of $\mathrm{Al}$ and $\mathrm{Ce}$ oxides, a composite film containing mixed $\mathrm{Al}_{2} \mathrm{O}_{3}$ and $\mathrm{Ce}_{2} \mathrm{O}_{3}$ (which would be converted into $\mathrm{CeO}_{2}$ ) oxides would be expected upon anodizing. The current overshoots at the onset of anodizing may be attributed to the sudden reaction of the metal surface to the electrolyte. Another explanation is described by Lohrengel in extended high field model where delayed oxide growth due to space charge region may be responsible for this initial current rise [59]. Therefore, the CV and EIS spectra at $1 \mathrm{~V}$ are excluded for analysing data. For each composition, the charge consumed during incremental growth is directly obtained from current density, which was further used to calculate the $k$-factor from film thickness (Faraday's law) in terms of molar mass, oxidation state, and oxide density assuming mixed matter theory. A coulometric analysis allows the determination of thickness $\Delta d$ using the following equation:

$\Delta d=\frac{M_{o x}}{z F \rho_{o x}} \Delta q_{o x}$

in which $\mathrm{M}_{\mathrm{ox}}=$ molar mass of oxide, $F=$ Faraday's constant, $q_{o x}=$ charge consumed in oxide formation. A detailed description of the coulometric analysis of the $k$-factor estimation can be found elsewhere $[6,60,61]$. Eq. (1) would lead to the determination of $k$ according to the following equation:

$k_{\text {ave }}=\sum_{i=1}^{n}\left[\frac{\Delta d}{\Delta V}\right]$

The density and molecular masses of mixed anodic film locally grown on the Al-Ce alloys were calculated using the mixed-matter theory as a function of initial metal concentrations by means of linear distributions between the $\mathrm{Al}_{2} \mathrm{O}_{3}$ and $\mathrm{Ce}_{2} \mathrm{O}_{3}$. For instance, for 10 at.\% Al-Ce alloy, $M_{\mathrm{ox}}$ was obtained by using the rule of mixture as $0.1 \mathrm{M}_{\mathrm{Ce}_{2} \mathrm{O}_{3}}+0.9 \mathrm{M}_{\mathrm{Al}_{2} \mathrm{O}_{3}}$. It is worth mentioning here that because of the nano-scale nature of ultra-thin films $(\sim 10-20 \mathrm{~nm})$ and lack of thermodynamic information for a particular electrolyte, the detection of specific mixed-oxide phase among many stable and metastable metal oxides (MOs) is very challenging at low voltages. The sophisticated techniques for the quantitative determination of film composition, in particular the RBS consume a lot of time. Additionally, novel procedures are required to obtain noisefree data using the above-mentioned techniques for accurate determination of film compositions. For instance, obtaining a smooth RBS spectrum and its simulation for a $10 \mathrm{~nm}$ film is very challenging. Likewise, slicing a stable film from a glass substrate using focused ion beam (FIB) and microtome for TEM examination is very difficult. RBS, FIB-TEM, microtome-TEM techniques generally 


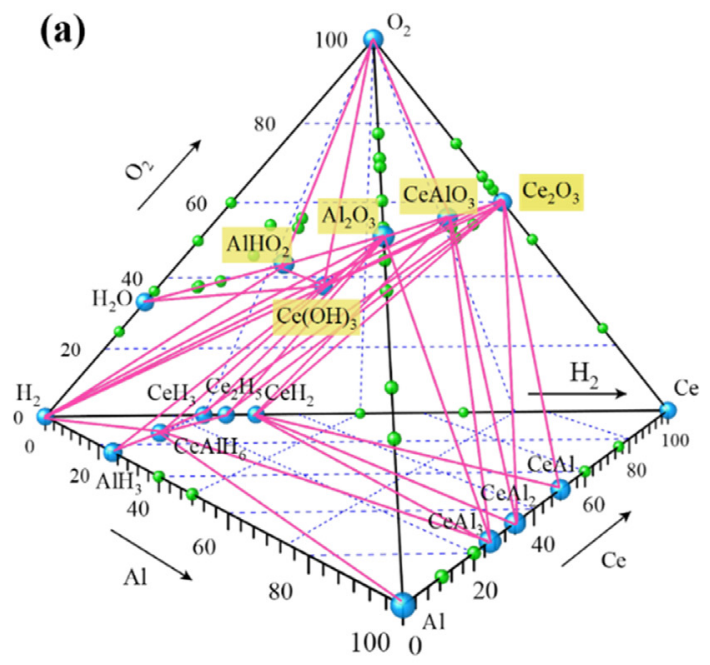

(c)

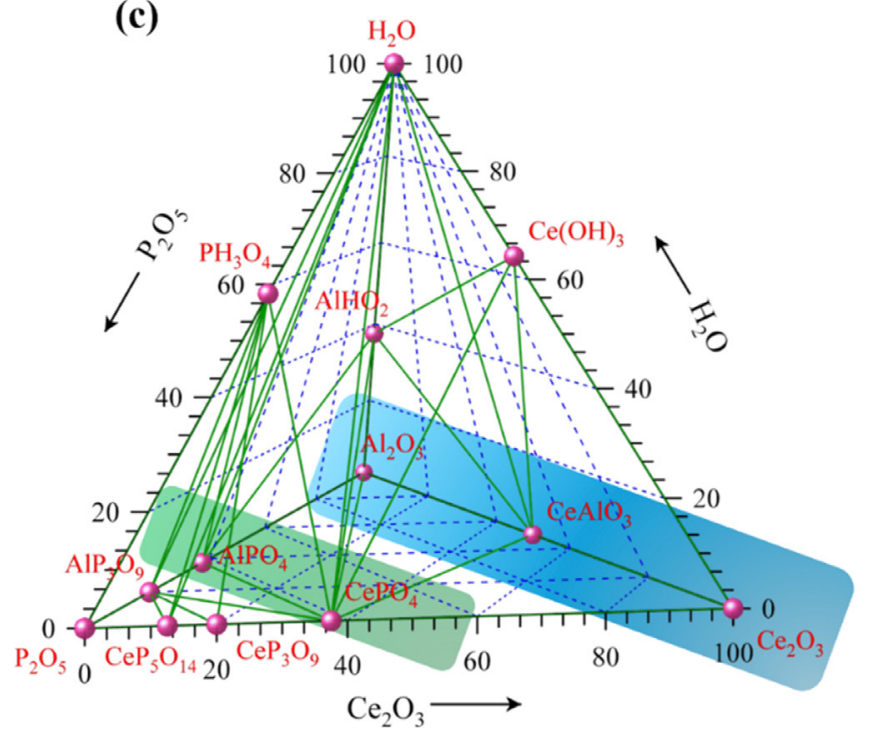

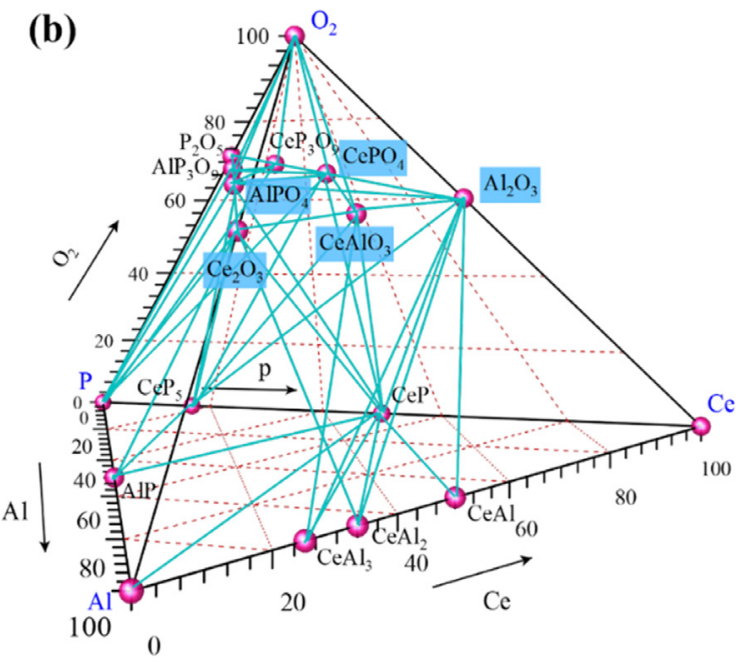

(d)
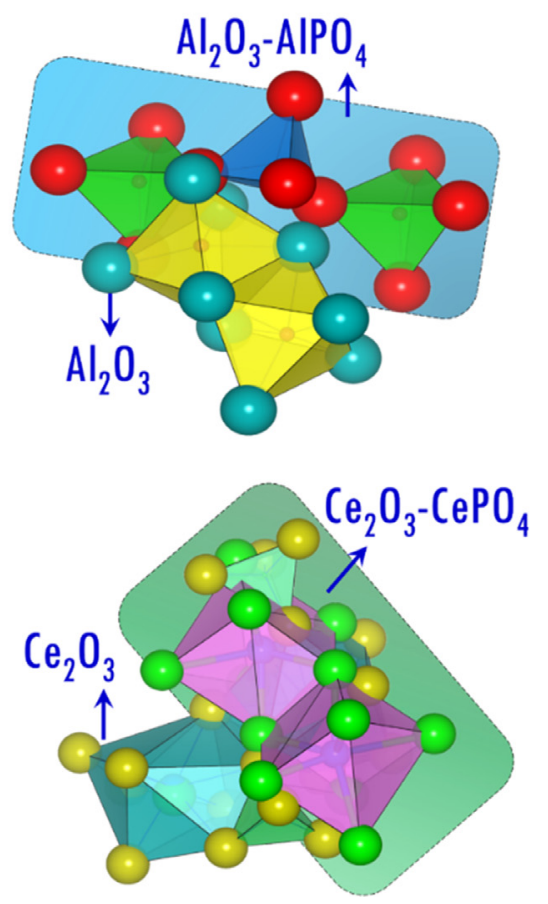

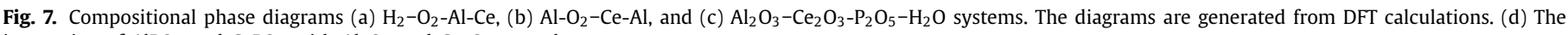
interaction of $\mathrm{AlPO}_{4}$ and $\mathrm{CePO}_{4}$ with $\mathrm{Al}_{2} \mathrm{O}_{3}$ and $\mathrm{Ce}_{2} \mathrm{O}_{3}$ crystals.

require a metallic substrate and the use of glass substrate is not a suitable choice for these measurements. Therefore, the abovementioned state-of-the-art techniques are virtually not practicable to map the compositionally graded libraries which may contain many alloys and may require special procedures for sample preparation too. Hence, an assumption is made for the oxidation of $\mathrm{Al}^{3+}$ and $\mathrm{Ce}^{3+}$ species based on experimentally proven literature for Al-RE alloys that the oxidation of alloying elements depends on Gibbs free energy per equivalent for the formation of alloying element oxide relative to that of formation of alumina. A more negative value relative to alumina indicates that alloying element has higher mobility than $\mathrm{Al}$ and this will result in immediate oxidation of $\mathrm{Ce}$ and $\mathrm{Al}[37,62-65]$. As Ce species migrates faster than $\mathrm{Al}^{3+}$ during anodizing Al-Ce alloys [37], it is likely that both $\mathrm{Al}$ and
Ce ions will be incorporated into the oxide film and form units of oxides.

In order to further validate our assumption of mixed-oxide formation, high-throughput DFT simulations were performed on various complex systems such as Al-Ce- $\mathrm{H}_{2}-\mathrm{O}_{2}, \mathrm{Al}-\mathrm{Ce}-\mathrm{P}-\mathrm{O}_{2}, \mathrm{Al}_{2} \mathrm{O}_{3}-$ $\mathrm{Ce}_{2} \mathrm{O}_{3}-\mathrm{P}_{2} \mathrm{O}_{5}-\mathrm{H}_{2} \mathrm{O}$ (Fig. 7) using Gibbs free energy minimization criteria and found out that only stable phases are $\mathrm{Al}_{2} \mathrm{O}_{3}, \mathrm{Ce}_{2} \mathrm{O}_{3}$ (which will convert to $\mathrm{CeO}_{2}$ ). $\mathrm{CeAlO}_{3}, \mathrm{AlPO}_{4}$, and $\mathrm{CePO}_{4}$. A phase diagram can be predictable from the DFT method by providing the energies of all known compounds in a given chemical system. A summary of formation energies, $\Delta H_{f}^{298 K}$ for some species in AlCe-P-H-O system from DFT calculations is provided in Table 3. Furthermore, oxide grown in phosphate buffer were assumed to be of pure nature without incorporation of phosphate species from the 


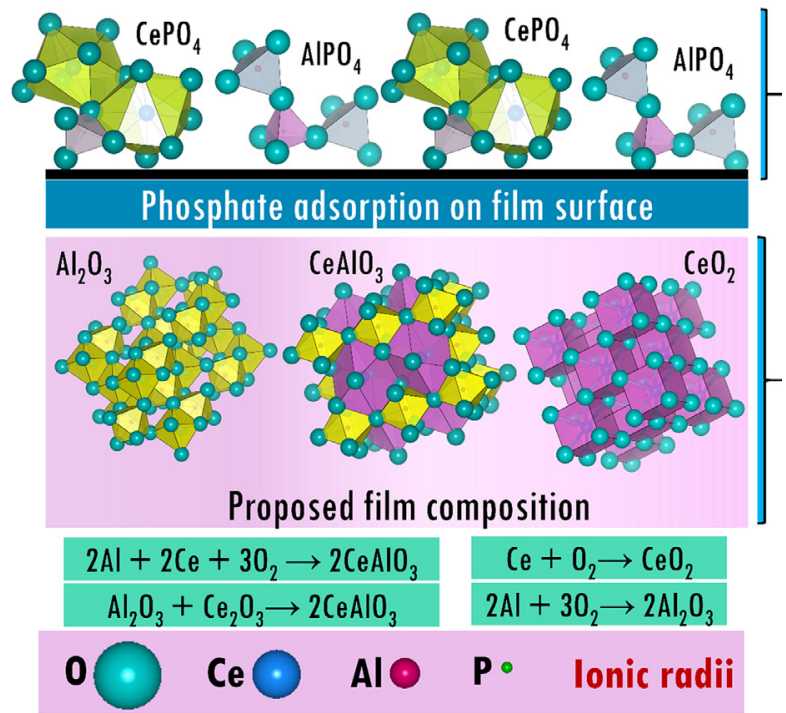

Fig. 8. Proposed composition of mixed anodic film. Comparison of ionic radii and phosphate adsorption on film surface is also shown.

electrolyte and because of the large size of phosphate-containing compounds as can be seen from the interaction of $\mathrm{Al}_{2} \mathrm{O}_{3}$ and $\mathrm{Ce}_{2} \mathrm{O}_{3}$ crystals with $\mathrm{AlPO}_{4}$ and $\mathrm{CePO}_{4}$ (Fig. 7d). Thus, the expected model of mixed-oxide growth in Al-Ce-P-H-O system using DFT calculations is schematically shown in Fig. 8.

\subsection{Electrochemical impedance spectroscopy}

One of the objectives of the current investigation was to explore the systematic correlation between film properties and alloy composition. Therefore, the combined CV-EIS approach is used to simultaneously investigate the response of growing films with $1 \mathrm{~V}$ increment of oxide growth. EIS is generally considered as a noninvasive research-based technique that separates system components in different frequency domains such as electrolyte and film resistances, diffusion parameters, and system capacitance, which otherwise cannot be achieved in steady-state measurements. For instance, high-frequency impedance spectra are often used to estimate the film capacitance, while film resistence usually appears in low-frequencey EIS measurements. Fig. 9a-f shows the series of Bode and Nyquist plots measured at extremes and middle composition for three Al-Ce alloys. Impedance changes linearly as a function of frequency and gradually rises with formation voltage at a negative slope, suggesting a linear growth of the film. An expected shift of phase angle towards $-90^{\circ}$ is obtained with increasing voltage for all compositions, which is a typical characteristics of anodic dielectric materials. The maximum phase shifts of $-89^{\circ},-84^{\circ}$, and $-81^{\circ}$ were obtained for Al-2 at.\% Ce, Al-5.5 at.\% Ce, Al-10.5 at.\% Ce, respectively. Apparently, Bode plots in log scale show similar absolute impedance regardless of film composition, although, phase shift plots disclose different response. This is because of the fact that absolute impedance is plotted on a log-log scale while the phase shift is not expressed on a log-log scale. The gradual reduction of real and imaginary component of impedance in the Nyquist plot (linear scale) clearly reveals the composition effect on impedance response (Fig. 9b, 9d, 9f). Moreover, phase shift discloses that incremental voltage rise not only induces a capacitive response as evident from the magnitude of phase angle but also widens the constant phase element (CPE) as oxide grows to a thicker and more resistive film. The impedance of film-covered electrode associated with CPE is generally expressed as

$Z_{C P E}=\frac{1}{Q(j \omega)^{\alpha}}$

It is worth to mention here that special consideration has been taken to understand the CPE and determination of C from CPE. The capacitance of electrochemical systems is used to calculate film properties, particularly the relative permittivity, layer thickness, and active surface area. The determination of C from CPE is often inadequate, leading to the erroneous prediction of the physical properties [66] This is simply a result of the physical background of the system e.g. a distribution of a physical variable such as composition or roughness. It may be appear surprising, that the CPE being a mathematical description only requires two variable parameters $Q$ and $\alpha$ to accurately fit the EIS spectra coming from a broad range of experiments. Independent of the origin of $\mathrm{CPE}$, the phase angle and $Q$ associated with CPE are independent of frequency. When $\alpha=1, Q$ has units of capacitance, i.e., $F \mathrm{~cm}^{-2}$, and resembles as an ideal capacitor. When $\alpha \neq 1, Q$ has units of $s^{\alpha} / \Omega$ $\mathrm{cm}^{2}$ [66]. In consistency with numerous literatures, our analysis also shows that impedance spectra are fitted well with the CPE compared with a true capacitor. The Fig. $10 \mathrm{a} \& \mathrm{~b}$ shows an EIS spectra fitting using Randles-type equivalent circuit which consists of electrolyte resistance, $R_{e l}$ in series with the parallel combination of $C_{o x}$ and $R_{f}$. The fitting gives a chi-square value of $10^{-2}$ (Fig. 10a) when using true capacitance, $C$ in parallel with $R_{f}$, while a value of $10^{-4}$ is obtained when $C$ is replaced by CPE having parameters $Q$ and $\alpha$ (Fig. 10b). Moreover, it must be noted in Fig. $10 \mathrm{~b}$ that ratio $\left(R_{f} / R_{e l}\right)$ between film resistance $\left(R_{f}\right)$ and electrolyte resistance $\left(R_{e l}\right)$ plays a significant role in widening CPE. A resistance ratio of $10^{4}$ causes significant broadening of CPE at $10 \mathrm{~V}$ compared with $10^{3}$ at $1 \mathrm{~V}$ (Fig. 10b). Thus, the pseudo-CPE in the global impedance response might occur owing to increase of $R_{f}$ with voltage as negligible change in $R_{e l}$ has been observed in all measurements.

As discussed before, CPE with parameters $\alpha$ and $Q$ cannot represent the true capacitance, thereby, conversion of $Q$ into $C$ is crucial. Several researchers have explored the relationship between interfacial capacitance and CPE and different equations were proposed in the past to convert $Q$ into $C$. Brug et al. [67] or Hsu and Mansfeld [68] expressions are normally used for true capacitance extraction from CPE. Brug's formula (originally derived for blocking electrode) and Hsu-Mansfeld equation results in different values of true capacitance for a given set of CPE parameters and in many cases both equations have been used to the similar systems. Mansfeld and Hsu proposed that $C$ value can be attained from log $f$ vs $-Z_{\text {img }}$ plot by considering the following relation.

$C=Q\left(\omega_{\max }\right)^{\alpha-1}$

where $\omega_{\max }$ is the frequency at which the imaginary component of impedance has the maximum value. Orazem et al. [69] and Hirschorn et al. [66] recently proposed that CPE arises owing to distributed time constants along the surface or normal to the electrode. Their formulations based on surface and normal distributions of time constants are presented in Eqs. (5)-(7).

$C_{\text {normal }}=Q^{\frac{1}{\alpha}}\left(R_{f}\right)^{(1-\alpha) / \alpha}$

$C_{\text {surface }}=Q^{\frac{1}{\alpha}}\left(\frac{R_{f} R_{e l}}{R_{f}+R_{e l}}\right)^{(1-\alpha) / \alpha}$ 

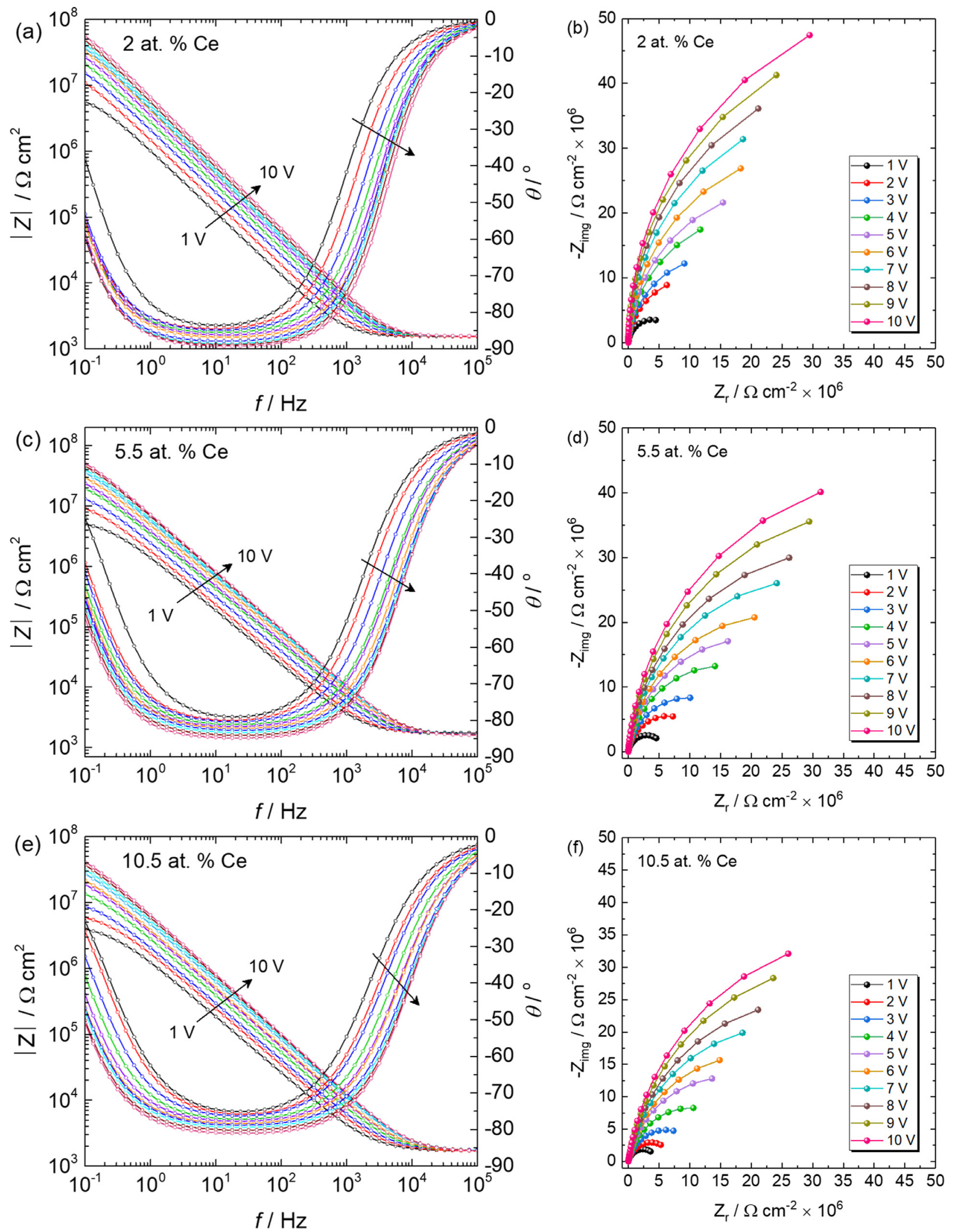

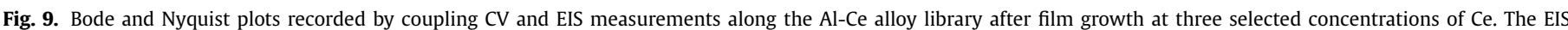
spectra were recorded with $1 \mathrm{~V}$ increment in $\mathrm{CV}$ to a maximum of $10 \mathrm{~V}$. 

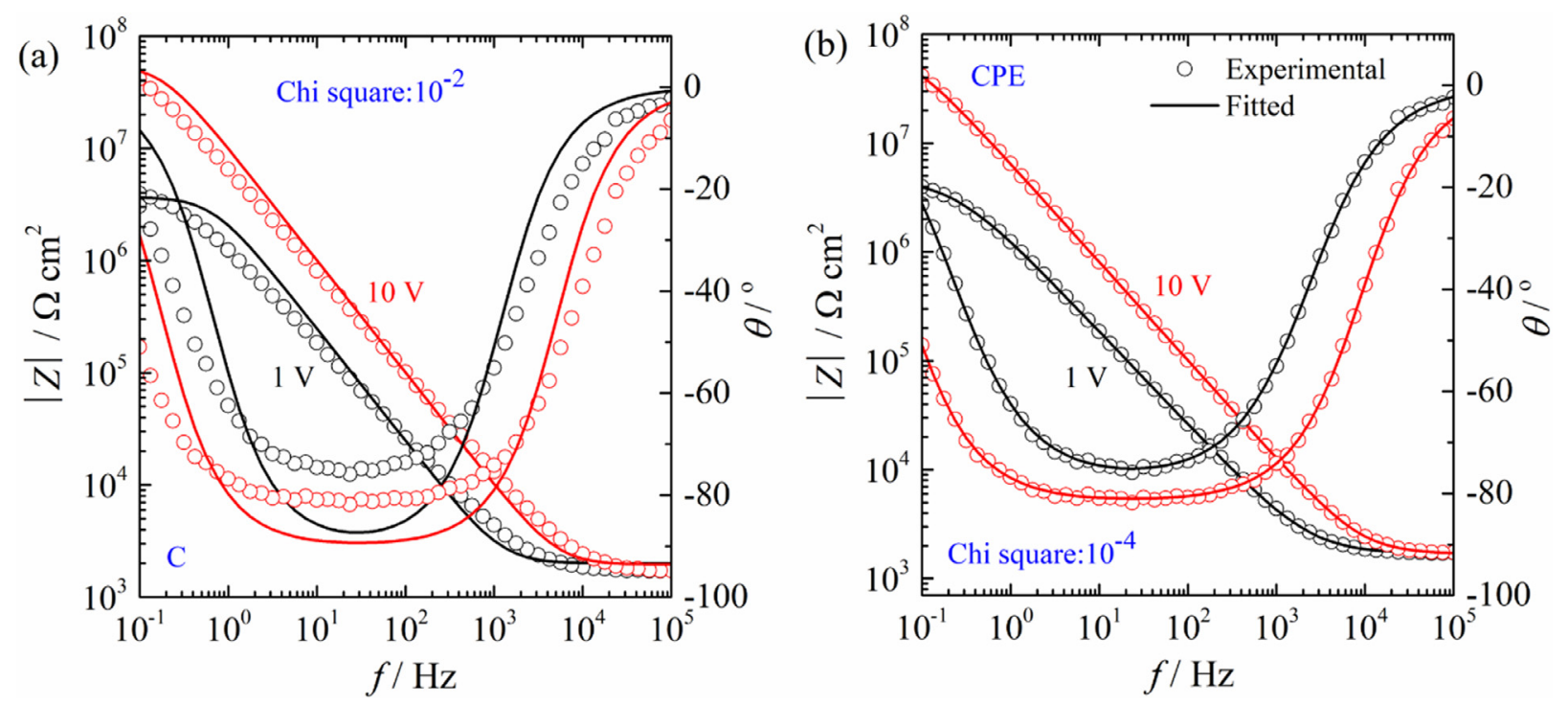

Fig. 10. Comparison of fitting by using $C$ and CPE having parameters $Q$ and $\alpha$ for an Al-3.0 at. Ce alloy.

In the limiting case, when $R_{f}$ becomes infinitely large, the above equation reduces to

$C_{\text {surface }}=Q^{\frac{1}{\alpha}}\left(R_{e l}\right)^{(1-\alpha) / \alpha}$

In the case of distributed time constants along the surface, the global impedance response of the electrode may include additional contributions from each part of the electrode surface. In the case of normal distribution for a thin layer of oxide having gradient in composition, the global impedance response of the electrode must incorporate additive contributions from each part of the layer. In the present research, the true capacitance, $C_{O X}$ from CPE is estimated by using different CPE-C conversion models for the computation of $k$ in addition to $k$-factor determination from Faraday's law. The $k$-factor from $C_{o x}$ was acquired by using the following relation.

$C_{o x}=\frac{\varepsilon_{o} \varepsilon_{o x} A}{d}=\frac{\varepsilon_{o} \varepsilon_{o x} A}{k V}$

For the applicability of surface and normal distributed approaches, it was necessary to get EIS spectra with well-defined $R_{f}$ and $\alpha$ values. Generally, the noisy Cole-Cole plots often lead to erroneous $R_{f}$ values from the fitted EIS spectra, which yield less precise $C_{o x}$ (Eqs. (5)-(7)). Therefore, composition dependent $R_{f}$ and $\alpha$ are estimated by fitting the EIS spectra and are presented in Fig. $11 \mathrm{a} \& \mathrm{~b}$. The computed parameters such as formation factor, $k$, dielectric permittivity, $\varepsilon_{o x}$ and film thickness ratio from EIS and Farday's equation are summarised in Fig. 11c \& d.

\subsection{Dielectric constant}

The relative permittivity number or dielectric constant, $\varepsilon_{o x}$ of the films was determined from the slopes of formation potential and inverse capacitance by using the following relation.

$C^{-1}=\frac{1}{A \varepsilon 0 \times \varepsilon 0}(d+d o)=\frac{k}{A \varepsilon 0 \times \varepsilon 0} V+\frac{d o}{A \varepsilon 0 \times \varepsilon 0}$

in which $V$ is the formation potential, $k$ is the oxide formation factor, $d_{o}$ is the thickness of the naturally grown-oxide film before anodizing, $\varepsilon_{0}$ is the permittivity of free space $\left(8.854 \cdot 10^{-14} \mathrm{~F} \mathrm{~cm}^{-1}\right)$ and $\varepsilon_{0 x}$ is a factor or unitless number called the relative permittivity number of the oxide. The latter is often called dielectric constant. The slope of inverse capacitance and formation potential will lead to the estimation of the dielectric constant according to following relation.

$\varepsilon_{o x}=\frac{k_{a v e}}{m A \varepsilon_{0}}$

Fig. 11c shows the composition dependent $\varepsilon_{o x}$ values from the $k$-factor obtained from Eqs. $(1-2,10)$. It must be pointed out here that different assumptions were made for the determination of $k_{\text {ave }}$ in EIS and Faraday's law measurements. The Faraday's equation involves the calculation of $k_{\text {ave }}$ using mixed matter theory and charge density approach including side reactions, which can be directly used for $\varepsilon_{o x}$ determination according to Eqs. $(1-2,10)$. While for EIS measurement, $k$-factor in Eq. (8) was calculated by using the experimentally determined $\varepsilon_{0 x}$ values for $\mathrm{Al}_{2} \mathrm{O}_{3}\left(\varepsilon_{\mathrm{Al}_{2} \mathrm{O}_{3}}=10.0\right)$ and $\mathrm{Ce}_{2} \mathrm{O}_{3}\left(\varepsilon_{\mathrm{Ce}_{2} \mathrm{O}_{3}}=14.6\right)$. [70] For instance, for 10 at.\% Al-Ce alloy, a value of $\sim 10.5$ was obtained according to $0.1 \varepsilon_{\mathrm{Ce}_{2} \mathrm{O}_{3}}+0.9 \varepsilon_{\mathrm{Al}_{2} \mathrm{O}_{3}}$. The values of $k$-factor in both measurements can only be comparable with the correct assumptions of material constants, precise $C_{0 x}$ estimation, and negligible contribution from side reactions. For instance, if $50 \%$ of the total charge consumption is due to the gas evolution this would double the $k$-value according to Eqs. (12). Similarly, an erroneous assumption of $\varepsilon_{0 x}$ from literature and wrong prediction of CPE-C conversion model would lead to significantly different $k$-factor compared with $k$-Faraday's law value. From the comparison of $k$-factor (Fig. 11d), it was also found that Mansfeld equation and normal distribution of time constants yield similar true capacitances, while the surface distribution or Brug's formula caused by the non-uniform distribution of currents and potentials along the surface gives a wrong estimation of $k$ values. In other words, surface distribution with negligible contribution from $R_{f}$ is not very effective for studies on passive films.

\subsection{Comparison of film thickness}

The film thickness ratio was also compared by considering the following relation.

$\eta=\frac{d_{\text {Faraday's }}}{d_{\text {EIS }}} \times 100$

The $k$-factor $(d=k \times V)$ from EIS measurements involves the calculation of film thickness directly resulting from the film, while Faraday's law requires the anodizing charge to be used directly for the determination of $d$ values. The identical $k$-values from Fara- 

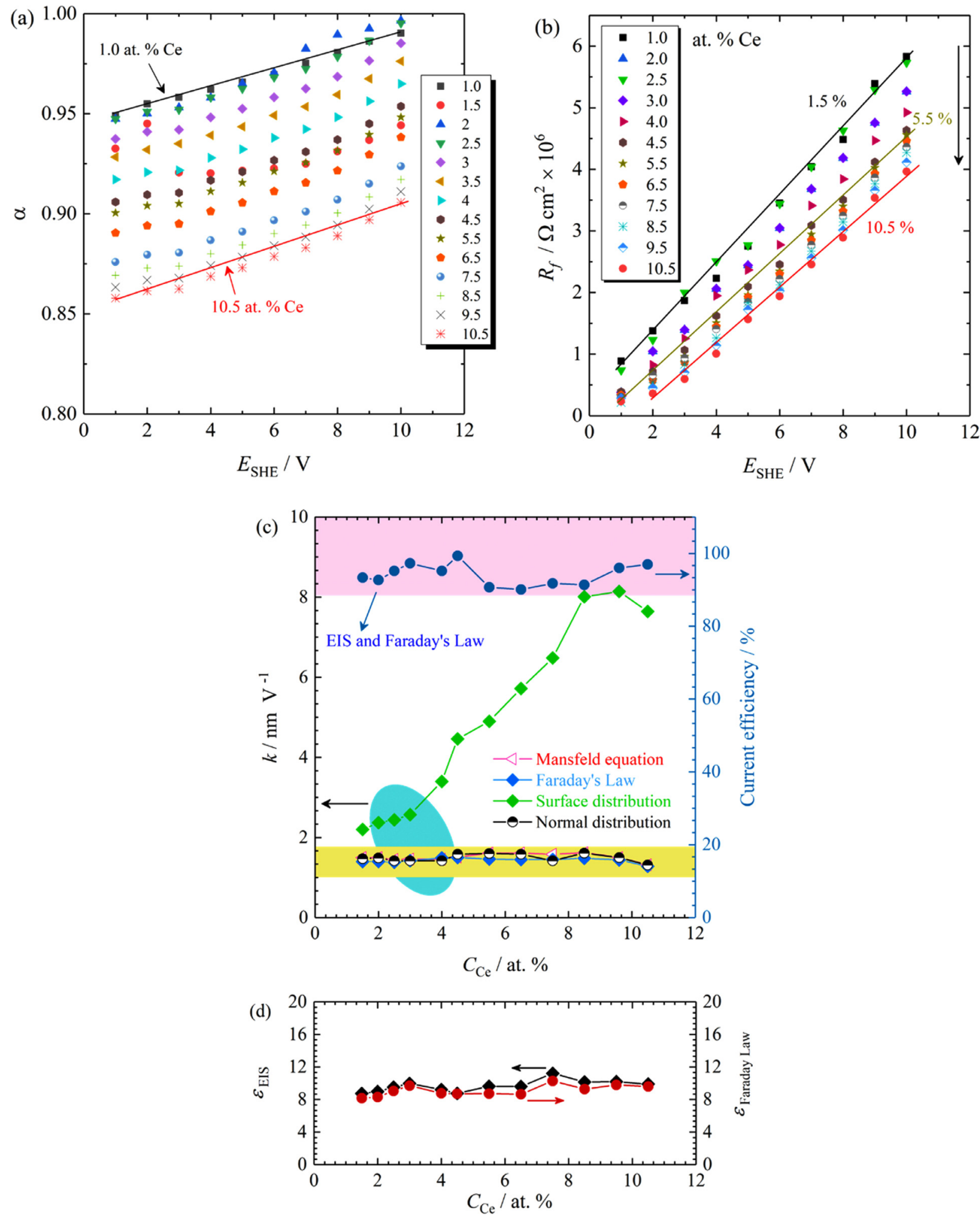

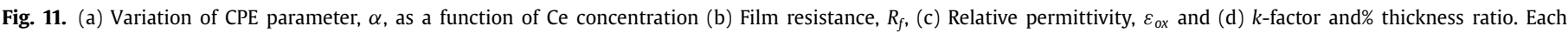
composition in Fig. c \& d is obtained from average values between 1 and $10 \mathrm{~V}$.

day's law and EIS measurements using the assumptions of mixed matter theory and $\varepsilon_{o x}$ values from the published literature lead to the film thicknesses ratio over $90 \%$ in a wide range of $\mathrm{Al}-\mathrm{Ce}$ alloy composition. The reduction in ratio from $100 \%$ might occur because of above-mentioned assumptions. The precise calculations of film thickness and hence the film growth efficiency further requires the in-situ metal dissolution monitoring using a combina- tion of SDCM and ICP-MS approach, such as the recent investigation from J. P. Kollender et al. [41] on the in-situ metal dissolution. The quantification of metal dissolution and gas evolution in different electrolytes and procedure optimization is the subject of future study. Moreover, a better understanding of CPE-C conversion models and CPE- $R_{f}$ is needed to improve the thickness calculation from EIS analysis. 
It should be also emphasized here that all impedance spectra were recorded at $0 \mathrm{~V}$ SHE. Under these conditions the charge carrier injection at this very low field is minimised as well as a possible band bending. Under these conditions direct elastic tunnelling is very unlikely. There are various ways to influence the number of charge carriers in the tunnelling path to change to resonance tunnelling. That may be the case if the potential difference is changed and defects are moved into the isoenergetic tunnelling path. That is often the case for high potentials since they bring in the band-near donor or acceptor levels [71]. These regions of band bending are often not accessible for large band gaps since the field strength would be too high resulting in a breakdown of the film [72]. They become however, accessible if photoelectrochemical measurements are performed which do not require high potentials as they are not probing an isoenergetic path in the oxide but provides the energy difference between band edge and donor or acceptor level [73]. Only under specific conditions such as low temperatures the change from elastic tunnelling through a trapezoidal barrier to Fowler Nordheim tunnelling through the remaining triangular barrier can be determined directly as a maximum in the first derivative of the logarithm of tunnelling current over the tunnelling voltage [74]. As an alternative high field strength conditions can be used to generate a manifold of charge carriers that are flooding the forbidden zone and act as stepping stones for electrons generating a decent conducting path for electrons. This was proven by the independent measurement of oxide formation and oxygen evolution on titanium [41].

Under the above said low voltages the graphical method of slope determination can be applied directly. Here the reciprocal of the capacity is plotted over the potential and the slope of the resulting line is proportional to $\varepsilon_{o x}$. The current method of calculating $\varepsilon_{o x}$ gives a value of 10.1 for $\mathrm{Al}$, which is close to the values reported by many researchers for bulk and thin-films on Al. As can be seen in Fig. 11d, $\varepsilon_{o x}$ values ranges from $8-10$ for Al-Ce alloys indicating that $\mathrm{Ce}$ incorporation to $\mathrm{Al}$ alloys not only displays the similar anodic film characteristics as can be seen from CVs in Fig. 6 but also gives film materials of identical dielectric strength as of alumina. These values are somewhat lower than the value reported by Xue et al. for $\mathrm{Ce}_{2} \mathrm{O}_{3}\left(\varepsilon_{o x}\right.$ for $\mathrm{Ce}_{2} \mathrm{O}_{3}=14.60$ ) [70].

In summary, good chemistry among chosen electrolyte based on Gibbs free energies information and experimental observations of film growth on Al-Ce combinatorial alloys has been demonstrated. All analysis must be interpreted from the used electrolyte point view. The simulation and modification of Eh-pH diagrams for a given alloy- $\mathrm{H}_{2} \mathrm{O}$ system is a powerful approach to understand the electrochemistry of grown oxide film compared with trial and error approach. It was expected that high concentration of Ce tends to impose its anodizing effect on the $\mathrm{Al}-\mathrm{Ce}$, but surprisingly, the very similar trend in oxide growth as of anodic alumina has been determined with a $k$-factor as high as 1.5 for Al-9.5 at.\% Ce.

This suggests an important conclusion that high strength passive films may be readily fabricated from anodic polarization process, which may expand the mechanical applications of these films at much higher temperature. When alloying an element with another this does not only have drastic effects on the properties of the bulk material but also on the surface properties which are often decisive for whether or not a material can be used. Al as an ignoble metal would readily react with its environment if there would not be the passive layer forming on its surface. Thus, an addition of an element like Ce can also have a drastic influence on the applicability through the modified oxide film forming on the alloy.

\section{Conclusions}

(1) Mixed-oxide anodic films are synthesized by potential sweep method on Al-Ce combinatorial alloys using automated scan- ning droplet microscopy in phosphate buffer. The modified potential-pH diagrams in $\mathrm{Al}-\mathrm{H}_{2} \mathrm{O}-\mathrm{P}$ and $\mathrm{Ce}-\mathrm{H}_{2} \mathrm{O}-\mathrm{P}$ systems allow us to rapidly predict the $\mathrm{pH}$ range and electrolyte selection.

(2) Thermal co-evaporation of Al-Ce alloys results in the formation of crystalline alloys in most composition ranges with predominantly $\mathrm{Al}$ (111) peaks, while 10.5 at.\% Ce induces amorphization in the parent alloy as proven by XRD.

(3) Cyclic voltammograms indicate that typical valve metal characteristics is obtained by the addition of Ce content as high as 10.5 at.\%. Thus, anodic films on Al-Ce alloys similar to the typical alumina films can be readily developed with this combinatorial approach.

(4) Electrochemical measurements reveal that similar valve metal response regardless of film composition. Film thickness, dielectric permittivity, and formation factor were estimated for the given Ce concentrations\% in the alloy while maintaining the added strength from Ce metal.

Figure 12. Determination of dielectric permittivity, $\varepsilon_{o x}$ from inverse capacitance and formation voltage. The slope for Al anodizing is also shown as reference.

\section{Declaration of Competing Interest}

The authors declare that they have no known competing financial interests or personal relationships that could have appeared to influence the work reported in this paper.

\section{Credit authorship contribution statement}

Khurram Shahzad: Methodology, Formal analysis, Investigation, Writing - original draft, Visualization. Shaukat Ali Lone: Formal analysis, Investigation, Visualization. Cezarina Cela Mardare: Investigation, Formal analysis, Visualization, Writing - original draft. Andrei Ionut Mardare: Software, Validation, Data curation, Writing - original draft, Visualization. Achim Walter Hassel: Conceptualization, Methodology, Validation, Resources, Data curation, Writing - original draft, Project administration, Funding acquisition.

\section{Acknowledgement}

The financial support by the Austrian Federal Ministry for Digital and Economic Affairs and the National Foundation for Research, Technology and Development in the frame of the Christian Doppler Laboratory for Combinatorial Oxide Chemistry (COMBOX) is gratefully acknowledged.

\section{References}

[1] H. Koinuma, I. Takeuchi, Combinatorial solid-state chemistry of inorganic materials, Nat. Mater. 3 (7) (2004) 429-438.

[2] C.C. Fischer, K.J. Tibbetts, D. Morgan, G. Ceder, Predicting crystal structure by merging data mining with quantum mechanics, Nat. Mater. 5 (8) (2006) 641-646.

[3] S. Curtarolo, G.L.W. Hart, M.B. Nardelli, N. Mingo, S. Sanvito, O. Levy, The high-throughput highway to computational materials design, Nat. Mater. 12 (3) (2013) 191-201.

[4] R. Collette, Y. Wu, A. Olafsson, J.P. Camden, P.D. Rack, Combinatorial thin film sputtering AuxAl1-x alloys correlating composition and structure with optical properties, ACS Comb. Sci. 20 (2018) 633-642.

[5] A.I. Mardare, A. Ludwig, A. Savan, A.W. Hassel, Scanning droplet cell microscopy on a wide range hafnium - niobium thin film combinatorial library, Electrochim. Acta 110 (2013) 539-549.

[6] A.I. Mardare, A. Ludwig, A. Savan, A.W. Hassel, Properties of anodic oxides grown on a hafnium-tantalum-titanium thin film library, Sci. Technol. Adv. Mater. 15 (2014) 1-11.

[7] Z. Hu, S. Haneklaus, G. Sparovek, E. Schnug, Rare earth elements in soils, Commun. Soil Sci. Plant Anal. 37 (9-10) (2006) 1381-1420.

[8] J.C.K. Lee, Z. Wen, Pathways for greening the supply of rare earth elements in China, Nat. Sustain. 1 (2018) 598-605.

[9] C. Bouzigues, T. Gacoin, A. Alexandrou, Biological applications of rare-earth based nanoparticles, ACS Nano 5 (2011) 8488-8505. 
[10] B. Johansson, W. Luo, S. Li, R. Ahuja, Cerium; Crystal structure and position in the periodic table, Sci. Rep. 4 (2014) 1-5.

[11] G.K. Muecke, P. Moller, The not-so-rare earths, Sci. Am. INC (1987) 72-77.

[12] C. Xu, X. Qu, Cerium oxide nanoparticle: a remarkably versatile rare earth nanomaterial for biological applications, NPG Asia Mater. 6 (2014) e90 -16.

[13] D.J. Smythe, J.M. Brenan, Cerium oxidation state in silicate melts: combined $\mathrm{fO}_{2}$, temperature and compositional effects, Geochim. Cosmochim. Acta 170 (2015) 173-187.

[14] C. Sun, H. Li, L. Chen, Nanostructured ceria-based materials: synthesis, properties, and applications, Energy Environ. Sci. 5 (2012) 8475-8505.

[15] J. Graciani, K. Mudiyanselage, F. Xu, A.E. Baber, J. Evans, S.D. Senanayake, D.J. Stacchiola, P. Liu, J. Hrbek, J. Fernández Sanz, J.A. Rodriguez, Highly active copper-ceria and copper-ceria-titania catalysts for methanol synthesis from $\mathrm{CO}_{2}$, Science 345 (6196) (2014) 546-550.

[16] P. Fornasiero, R.D. Monte, G.R. Rao, J. Kaspar, S. Meriani, A. Trovarelli, M. Graziani, Rh-loaded $\mathrm{CeO}_{2}-\mathrm{ZrO}_{2}$ solid solutions as highly efficient oxygen exchangers: dependence of the reduction behavior and the oxygen storage capacity on the structural properties, J. Catal. 151 (1995) 168-177.

[17] S. Patil, S.C. Kuiry, S.; Seal, Vanfleet, R. Synthesis of nanocrystalline ceria particles for high temperature oxidation resistant coating, J. Nanoparticle Res. 4 (2002) 433-438.

[18] A. Corma, P. Atienzar, H. García, J.Y. Chane-Ching, Hierarchically mesostructured doped $\mathrm{CeO}_{2}$ with potential for solar-cell use, Nat. Mater. 3 (2004) 394-397.

[19] N. Imanaka, T. Masui, H. Hirai, G.Y. Adachi, Amorphous cerium-titanium solid solution phosphate as a novel family of band gap tunable sunscreen materials, Chem. Mater. 15 (2003) 2289-2291.

[20] A.B. Stambouli, E Traversa, Solid oxide fuel cells (SOFCs): a review of an environmentally clean and efficient source of energy, Renew. Sustain. Energy Rev. 6 (2002) 433-455.

[21] I. Celardo, J. Pedersen, E. Traversa, L. Ghibelli, Pharmacological potential of cerium oxide nanoparticles, Nanoscale 3 (2011) 1411-1420.

[22] P. Eriksson, A.A. Tal, A. Skallberg, C. Brommesson, Z. Hu, R.D. Boyd, W. Olovsson, N. Fairley, I.A. Abrikosov, X. Zhang, K. Uvdal, Cerium oxide nanoparticles with antioxidant capabilities and gadolinium integration for MRI contrast enhancement, Sci. Rep. 8 (2018) 1-12.

[23] J. Kaspar, P. Fornasiero, M. Grazian, Use of $\mathrm{CeO}_{2}$-based oxides in the three-way catalysis, Catal. Today 50 (1999) 285-298.

[24] C.K. Kim, T. Kim, I.Y. Choi, M. Soh, D. Kim, Y.J. Kim, H. Jang, H.S. Yang, J.Y. Kim, H.K. Park, S.P. Park, S. Park, T. Yu, B.W. Yoon, S.H. Lee, T. Hyeon, Ceria nanoparticles that can protect against ischemic stroke, Angew. Chem. Int. Ed. 51 (2012) $1-6$.

[25] S. Deshpande, S. Patil, S.V. Kuchibhatla, S. Seal, Size dependency variation in lattice parameter and valency states in nanocrystalline cerium oxide, Appl. Phys. Lett. 87 (2005) 1-3.

[26] Z.C. Sims, D. Weiss, S.K. McCall, M.A. McGuire, R.T. Ott, T. Geer, O. Rios, P.A.E. Turchi, High performance aluminum-cerium alloys for high-temperature applications, Miner. Met. Mater. Soc. 68 (7) (2016) 1940-1947.

[27] T.S. Sreeremya, K.M. Thulasi, A. Krishnan, S Ghosh, A novel aqueous route to fabricate ultrasmall monodisperse lipophilic cerium oxide nanoparticles, Ind. Eng. Chem. Res. 51 (2012) 318-326.

[28] H.L. Lin, C.Y. Wu, R.K. Chiang, J. Facile synthesis of $\mathrm{CeO}_{2}$ nanoplates and nanorods by [1 00 0] oriented growth, J. Colloid Interface Sci. 341 (2010) 12-17.

[29] S. Sathyamurthy, K.J. Leonard, R.T. Dabestani, M.P. Mp. Paranthaman, Reverse micellar synthesis of cerium oxide nanoparticles, Nanotechnology 16 (2005) 1960-1964.

[30] H. Gu, M.D. Soucek, Preparation and characterization of monodisperse cerium oxide nanoparticles in hydrocarbon solvents, Chem. Mater. 19 (2007) 1103-1110.

[31] L. Mädler, W.J. Stark, S.E. Pratsinis, Flame-made ceria nanoparticles, J. Mater. Res. 17 (2002) 1356-1362.

[32] S.K. Sahoo, M. Mohapatra, A.K. Singh, S. Anand, Hydrothermal synthesis of single crystalline nano $\mathrm{CeO}_{2}$ and its structural, optical, and electronic characterization, Mater. Manuf. Process. 25 (2010) 982-989.

[33] A.I. Mardare, C.C. Mardare, A.W. Hassel, Anodization behaviour and basic property mapping in the aluminium-erbium system, J. Solid State Electrochem. 22 (2018) 869-876

[34] A.I. Mardare, A. Savan, A. Ludwig, A.D. Wieck, A.W. Hassel, A combinatorial passivation study of Ta-Ti alloys, Corros. Sci. 51 (2009) 1519-1527.

[35] K. Shahzad, C.C. Mardare, D. Recktenwald, A.I. Mardare, A.W. Hassel, Formation of nano-scale composite anodic films on aluminium-holmium alloys, Electrochim. Acta 297 (2019) 888-904.

[36] C.M. Siket, N. Tillner, A.I. Mardare, A. Reuveny, C.D. Grill, F. Hartmann, G. Kettlgruber, R. Moser, J.P. Kollender, T. Someya, A.W. Hassel, M. Kaltenbrunner, S. Bauer, Direct writing of anodic oxides for plastic electronics, NPJ Flex. Electron. 2 (1) (2018) 23.

[37] A.C. Crossland, G.E. Thompson, P. Skeldon, G.C. Wood, C.J.E. Smith, H. Habazaki, K. Shimizu, Anodic oxidation of Al-Ce alloys and inhibitive behaviour of cerium species, Corros. Sci. 40 (6) (1998) 871-885.

[38] M. Bethencourt, F.J. Botana, JJ. Calvino, J. Marcos, M.A. Rodriguez-Chahon, Lanthanide compound as environmentally-friendly corrosion inhibitors of aluminium alloys, a review, Corros. Sci. 40 (11) (1998) 1803-1819.

[39] A.W. Hassel, M. Lohrengel, M The scanning droplet cell and its application to structured nanometer oxide films on aluminium, Electrochim. Acta 42 (1997) $3327-3333$
[40] K. Ogle, M. Mokaddem, P. Volovitch, Atomic emission spectroelectrochemistry applied to dealloying phenomena II. Selective dissolution of iron and chromium during active-passive cycles of an austenitic stainless steel, Electrochim. Acta 55 (2010) 913-921.

[41] J.P. Kollender, A.W. Hassel, In situ monitoring of ionic metal dissolution during anodization of titanium and quantification of parallel electronic oxygen evolution, ChemElectroChem 4 (2017) 1846-1848.

[42] M. Pourbaix, Atlas of Electrochemical Equilibria in Aqueous Solutions, 170-172, Pergamon Press Ltd., Houston, Texas, 1974, pp. 183-197.

[44] https://www.gwb.com/softwareoverview.php.

[44] https://www.gwb.com/.

[45] http://factsage.com/.

[46] https://sites.google.com/site/chemdiagr/.

[47] https://www.kth.se/che/medusa/downloads-1.386254.

[48] https://materialsproject.org/.

[49] K.A. Persson, B. Waldwick, P. Lazic, Ceder, Prediction of solid-aqueous equilibria: scheme to combine first-principles calculations of solids with experimental aqueous states, Phys. Rev. B Condens. Matter Mater. Phys. 85 (2012) 1-12.

[50] A. Jain, G. Hautier, C.J. Moore, S.P. Ong, C.C. Fischer, T. Mueller, K.A. Persson, G. Ceder, A high-throughput infrastructure for density functional theory calculations, Comput. Mater. Sci. 50 (2011) 2295-2310.

[51] K.A. Gschneidner, F.W. Calderwood, The Al-RE (Aluminum-Rare Earth) systems, Bull. Alloy Phase Diagr. 9 (1988) 658-668.

[52] T.B. Massalski, J.L. Murray, L.H. Bennet, H. Baker, L. Kacprazak, Binary Alloys Phase Diagrams, ASM, Ohio, 1986, p. 122.

[53] A.I. Mardare, C.D. Grill, I. Pötzelberger, T. Etzelstorfer, J. Stangl, A.W. Hassel, J Solid State Electrochem. 20 (2016) 1673-1681.

[54] F.H. Firsching, Solubility products of the trivalent rare-earth arsenates, J. Chem. Eng. Data 37 (1992) 497-499.

[55] E. Kim, K. Osseo-Asare, Aqueous stability of thorium and rare earth metals in monazite hydrometallurgy: Eh-pH diagrams for the systems Th-, Ce-, La-, Nd$\left(\mathrm{PO}_{4}\right)-\left(\mathrm{SO}_{4}\right)-\mathrm{H}_{2} \mathrm{O}$ at $25^{\circ} \mathrm{C}$, Hydrometallurgy $113-114$ (2012) 67-78.

[56] D.G. Brookins, Eh-pH diagrams for the rare earth elements at $25^{\circ} \mathrm{C}$ and one bar pressure, Geochem. J. 17 (1983) 223-229.

[57] D. Weiss, Castability and characteristics of high cerium aluminum alloys, Adv. Cast. Technol. (2018) 431.

[58] A.S. Kumar, A.R. Durai, T. Sornakumar, Development of alumina-ceria ceramic composite cutting tool, Int. J. Refract. Met. Hard Mater. 22 (2004) 17-20.

[59] M.M. Lohrengel, Thin anodic oxide layers on aluminium and other valve metals: high field regime, Mater. Sci. 12 (1993) 243-294.

[60] A. Michaelis, J.L. Delplancke, J.W. Schultze, Ellipsometric determination of the density of TiO passive films on Ti single crytals: combination of ellipsometry and coulometry, Mater. Sci. Forum. 185-188 (1995) 471-480.

[61] A.I. Mardare, A.P. Yadav, A.D. Wieck, M. Stratmann, A.W. Hassel, Combinatorial electrochemistry on Al-Fe alloys, Sci. Technol. Adv. Mater. 9 (3) (2008) 035009.

[62] J.M. Torrescano-Alvarez, M. Curioni, H. Habazaki, T. Hashimoto, P. Skeldon, $\mathrm{X}$. Zhou, Incorporation of alloying elements into porous anodic films on aluminium alloys: the role of cell diameter, Electrochim. Acta 296 (2019) 783-789.

[63] G.E. Thompson, H. Habazaki, K. Shimizu, M. Sakairi, G.C. Wood, Anodizing of aluminium alloys, Aircr. Eng. Aerosp. Technol. 71 (1999) 228-238.

[64] A.E. Herrera-Erazo, H. Habazaki, K. Shimizu, P. Skeldon, G.E. Thompson, Anodic film growth on Al-Nd alloys, Corros. Sci. 42 (2000) 1823-1830.

[65] H. Habazaki, P. Skeldon, G.E. Thompson, G.C. Wood, Anodic film formation on a sputter-deposited amorphous Al-40 at.\% Sm alloy, J. Mater. Res. 12 (7) (1997) 1885-1891.

[66] B. Hirschorn, M.E. Orazem, B. Tribollet, V. Vivier, I. Frateur, M. Musiani, Determination of effective capacitance and film thickness from constant-phase-element parameters, Electrochim. Acta 55 (2010) 6218-6227.

[67] G.J. Brug, A.L.G. van den Eeden, M. Sluyters-Rehbach, J.H.J. Sluyters, The analysis of electrode impedances complicated by the presence of a constant phase element, J. Electroanal. Chem. 176 (1984) 275-295.

[68] C.H. Hsu, F. Mansfeld, Concernng the conversion of the constant phase element parameter Y0 into a capacitance, Corros. Sci. Sect. 57 (9) (2001) 747-748.

[69] M.E. Orazem, I. Frateur, B. Tribollet, V. Vivier, S. Marcelin, N. Pebere, A.L. Bunge, E.A. White, D.P. Riemer, M. Musiani, Dielectric properties of materials showing constant-phase-element (CPE) impedance response, J. Electrochem. Soc. 160 (2013) C215-C225.

[70] D. Xue, K. Betzler, H. Hesse, Dielectric constants of binary rare-earth compounds, J. Phys. Condens. Matter. 12 (2000) 3113-3118.

[71] A. Zaffora, F.D. Franco, M. Santamaria, H. Habazaki, F.Q. Quarto, The influence of composition on band gap and dielectric constant of anodic Al-Ta mixed oxides, Electrochim. Acta 180 (2015) 666-678.

[72] A.W. Hassel, D. Diesing, Breakdown of ultrathin anodic valve metal oxide films, Thin Solid Films 414 (2002) 296-303.

[73] F.D. Franco, A. Zaffora, M. Santamaria, Band gap narrowing and dielectric constant enhancement of $(\mathrm{NbxTa}(1-\mathrm{x}))_{2} \mathrm{O}_{5}$ by electrochemical nitrogen doping, Electrochim. Acta 265 (2018) 326-335.

[74] Jeliazova, M. Kayser, B. Mildner, A.W. Hassel, D. Diesing, Temperature stability of thin anodic oxide films in metal/insulator/metal structures: a comparison between tantalum and aluminium oxide, Thin Solid Films 500 (2006) 330-335. 